\title{
Multi-objective Evolutionary Algorithms for Power Distribution System Reconfiguration
}

\author{
Ivo Benitez Cattani \\ Parque Tecnológico Itaipu, \\ Hernandarias, Paraguay, \\ ivo.benitez@pti.org.py \\ and \\ Enrique R. Chaparro \\ Universidad Nacional del Este, Facultad Politécnica, \\ Ciudad del Este, Paraguay, 7000, \\ enriquerchv@fpune.edu.py \\ and \\ Benjamín Barán \\ Universidad Nacional de Asunción, Facultad Politécnica, \\ San Lorenzo, Paraguay, 1330, \\ bbaran@pol.una.py
}

\begin{abstract}
In this paper, two reconfiguration methodologies for three-phase electric power distribution systems based on multi-objective optimization algorithms are developed in order to simultaneously minimize two objective functions, (1) power losses and (2) three-phase unbalanced voltage. The proposed optimization involves only radial topology configurations which is the most common configuration in electric distribution systems. The formulation of the problem considers the radial topology as a constraint, increasing the computational complexity. The Prim and Kruskal algorithms are tested to fix infeasible configurations. In distribution systems, the three-phase unbalanced voltage and power losses limit the power supply to the loads and may even cause overheating in distribution lines, transformers and other equipment. An alternative to solve this problem is through a reconfiguration process, by opening and/or closing switches altering the distribution system configuration under operation. Hence, in this work the three-phase unbalanced voltage and power losses in radial distribution systems are addressed as a multi-objective optimization problem, firstly, applying a Genetic Algorithm using the weighted sum method; and, secondly, implementing an NSGA-II algorithm. Examples of distribution systems are presented to prove the effectiveness of the proposed method.
\end{abstract}

Keywords: multi-objective optimization, weighted sum, distribution system reconfiguration, unbalance, losses, genetic algorithm.

\section{Introduction}

The power distribution system reconfiguration consists in altering the system topological structure by opening and closing some switching devices. In this paper, the reconfiguration is carried out as a multi-objective problem, which has a huge variety of configuration possibilities whose complexity depends on the number of switches and network topology. The problem complexity and the discrete nature of the switches make the reconfiguration a mixed integer nonlinear optimization problem. The number of possible network states 
grows exponentially with the number of switches $\left(2^{n}\right)$, making rudimentary techniques such as exhaustive search totally unsuitable [1].

In the last decades, there have been studies proposing optimization algorithms to provide good enough solutions since running all possible configurations requires a prohibitively long running time. Although these algorithms do not guarantee that a globally optimal solution is found, they often improve the initial configuration, such as the first heuristic method proposed by Merlin and Back [2], where a special variation of the branch and bound technique was employed to determine the minimum loss configuration; then Shirmohammadi and Hong [3] made improvements to this methodology through the analysis of optimal power flow. In 4], Civanlar et al. developed a heuristic methodology to reduce the losses of electrical networks, formulating a simple algebraic expression to estimate the power loss reduction via load transfer among feeders.

The fact that the above mentioned optimization techniques normally find just local optimum, has motivated the development of metaheuristic methods for distribution system reconfiguration in the early $90 \mathrm{~s}$. For example, in [5] a reconfiguration method for loss reduction in distribution systems was proposed using Genetic Algorithm. The same optimization problem was solved through Artificial Neural Networks [6] and Simulated Annealing [7. Later, an Ant Colony Algorithm was introduced to solve the optimal system reconfiguration for power loss reduction [8]. It can be noted that most of the studies on reconfiguration, only considers a single objective problem, typically loss reduction.

Problems with multiple objectives arise in a natural fashion in most disciplines and their solution has been a challenge to researchers for a long time [9]. In the same way, reconfiguration problems can also consider more than one objective, given that each configuration has different electrical parameters that can be better for a certain objective function but at the same time be worse for another one. Basically, there are two approaches to solve multi-objective optimization.

The easiest way to perform a multi-objective optimization is reformulating the multi-objective problem into a single objective one. In a reconfiguration problem, the classical weighted sum method was used in 10, 11 to maximize the average reliability and minimize the system power loss. The main drawback of this method is that it is not possible to depict the complete Pareto optimal set thoroughly for non-convex problems. Despite deficiencies with this method, the weighted sum method for multi-objective optimization continues to be extensively used 12 .

On the other hand, we have alternative multi-objective optimization algorithms to solve the reconfiguration problem; as the Multi-Objective Evolutionary Algorithms (MOEAs). They are able to obtain the Pareto optimal set even for non-convex problems. MOEAs seem particularly suitable to solve multi-objective optimization problems, because they deal simultaneously with a set of feasible solutions [9]. This allows to find several members of the Pareto optimal set in a single run of the algorithm, instead of having to perform a serie of separate runs, as needed when using weighted sum. For instance, in 13, 14, researchers proposed different MOEAs to minimize the system power loss and maximize the system reliability at the same time.

In order to test the performance of both approaches, this paper proposes, first, to apply a Genetic Algorithm (GA) using the weighted sum method and reformulate the multi-objective problem into a single objective problem, then applying a MOEA to solve the same multi-objective problems for optimal distribution system reconfiguration. The literature offers several MOEAs, such as NPGA (Niched Pareto Genetic Algorithm) 15, SPEA (Strength Pareto Evolutionary Algorithm) [16, SPEA-II [17, MOGA (Multi Objective Genetic Algorithm) [18, NSGA (Non-dominated Sorting Genetic Algorithm) [19], NSGA-II [20] and so on. In this paper, the NSGA-II algorithm will be implemented considering its well-known good performance in different engineering problems [21. In addition, the comparison of MOEAs for distribution system reconfiguration, performed by Mazza et al. 14, shows that the NSGA-II results have a good performance even in reconfiguration system problems.

The authors surveyed the state of the art in distribution system reconfiguration, and found that several objective functions were studied. However, according to their findings, the three-phase unbalanced voltage has not been carried out as an objective function yet.

The effect of unbalanced voltage can be severe on equipment such as induction motors, power electronic converters and adjustable speed drives 22. Unbalanced voltages can result in adverse effects on equipment and on the whole power system. Under unbalanced conditions, the power system will incur more losses and heating effects, and be less stable because when the phases are balanced, the system is in a better position to respond to emergency load transfers. An induction motor may be damaged and shorten its life for long-term or even short-term operation under an unbalanced condition 23 .

Considering the effects that unbalanced voltages can cause in distribution systems and the lack of research on the reconfiguration process used to correct unbalanced voltages, one objective function to be minimized in this paper will be the bus with the highest voltage unbalance index in the system. On the other hand, power loss minimization is already known as one of the main challenges in distribution system. Lower electricity losses are associated with better financial sustainability of utilities, as additional revenues increase 
cost recovery, enhance the capitalization of the power sector, and improve the sector's capacity to invest. Electricity losses are mainly concentrated in distribution systems, which accounts for up to $80 \%$ of total losses 24.

Considering the aforementioned importance of loss reduction in distribution system, the real power loss minimization will be the other objective function to be minimized. The objective functions (voltage unbalance index and power loss minimization) conflict with each other. Unlike single objective optimization, the solution to this problem is not a single one, but a family of trade-off solutions known as the Paretooptimal set [18. Each point in this set is optimal in the sense that no improvement can be achieved in any objective vector without a degradation in at least one of the remaining objective functions. Hence, the application of the Pareto concept is a reasonable solution to this multi-objective problem to obtain a set of non-dominated optimal solutions.

Computing the objective functions requires running a three-phase power flow study. There are many power flow methods for transmission systems; however, for three-phase distribution systems we can find just a few power flow methods. In this paper, the Ladder Iterative Technique or Forward and Backward Sweep, proposed in 25] will be implemented. This is one of the most effective three-phase power flow methods for distribution systems; it takes advantage of the radial structure of distribution systems making use of Kirchhoff's circuit laws, and it has excellent convergence characteristics.

Most electric distribution feeders are configured radially, for effective coordination of their protection systems [3]; consequently in this paper only radial distribution systems are considered. The radiality increases the computational complexity due to the reconfiguration process. The proposed Genetic Algorithm requires the application of mutation and crossover operators, which can cause infeasible configurations (non-radial configurations or configurations with isolated load buses). Therefore, constrains are applied in order to identify infeasible configurations. This paper proposes to deal with infeasible configurations as a MinimumSpanning-Tree problem in order to implement the Prim [26] or Kruskal [27] algorithms to fix unfeasible configurations. These algorithms have been used in several reconfiguration problems, such as 28, 29, 30.

The system presented in [4] is used to validate the reconfiguration algorithm comparing the results with a former publication. Moreover, the system loads are altered to test the algorithms in an unbalanced system, and then the system is extended to verify the efficiency of the proposed methods in larger unbalanced systems.

\section{Mathematical Model}

Prior to the problem formulation, the three-phase power flow algorithm must be developed, since the objective functions proposed in this paper are computed from the power flow outcomes. In this section, a three-phase power flow algorithm is summarized to obtain the required electrical parameters.

\subsection{Distribution System Modeling}

The mathematical model of the distribution system components are classified in two kind of components, Series Components and Shunt Components [31. They can be mathematically modeled as follows.

\subsubsection{Series Components}

The most common series components of distribution systems are Line Segments, Transformers and Voltage Regulators [31. The general model for series components are shown in Fig. 1 .

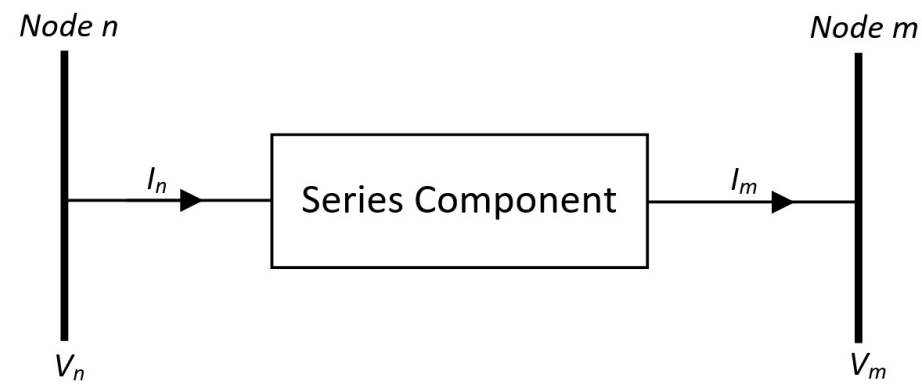

Figure 1: Mathematical Model of Series Component. 
The general equations (1), (2) and (3) relate the voltages and currents of Node $m$ and Node $n$ :

$$
\begin{aligned}
{\left[V_{a b c}\right]_{n} } & =[a] \cdot\left[V_{a b c}\right]_{m}+[b] \cdot\left[I_{a b c}\right]_{m} \\
{\left[I_{a b c}\right]_{n} } & =[c] \cdot\left[V_{a b c}\right]_{m}+[d] \cdot\left[I_{a b c}\right]_{m} \\
{\left[V_{a b c}\right]_{m} } & =[A] \cdot\left[V_{a b c}\right]_{n}-[B] \cdot\left[I_{a b c}\right]_{m}
\end{aligned}
$$

where the matrices $a, b, c, d, A$ and $B$, are general matrices relating to the kind of component connected between nodes $n$ and $m$. These matrices are computed by the methods proposed in 31.

\subsubsection{Shunt Components}

The most common shunt components of distribution systems are Spot Loads, Distributed Loads and Capacitor Banks [31]. These components, unlike series components, are connected only to a bus. They can be three-phase, two-phase, or single phase, and connected in either a wye or a delta connection. The shunt components are modeled in accordance with [31.

\subsection{Three-Phase Power Flow}

Fig. 2 represents a single line diagram of a radial system, which has been designed to describe the Forward and Backward Sweep algorithm.

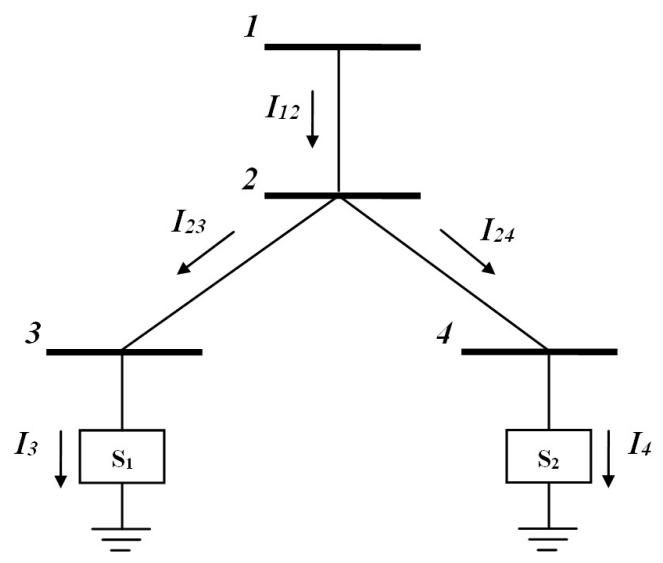

Figure 2: Single line diagram of a radial system.

The Forward and Backward Sweep method can start when all the components are modeled and the voltage in the source bus $\left(V_{1 \text { real }}\right)$ is known. This method has two steps that are specified in what follows.

Step 1 (Forward Sweep):

- For the first iteration, assume three-phase rated voltages at the end buses (in Fig. 2, buses 3 and 4).

- Compute the three-phase currents $I_{3}$ and $I_{4}$ with the assumed voltages according to the shunt components connected to each bus. The currents computed in Step 1 must be stored to be used in Step 2 .

- Compute the voltage at bus 2 using equation (1).

- Compute currents $I_{23}$ and $I_{24}$ using equation (2).

- Compute current $I_{12}$ using Kirchhoff's current law.

- Compute the voltage at bus 1 using equation (11).

- Check convergence, compare the computed voltage at bus 1 with the specified voltage $V_{1 \text { real }}$. The convergence is achieved if the difference is less than a specified tolerance (for instance, 0.0001), hence the method stops, otherwise Step 2 is executed.

Step 2 (Backward Sweep): 
- Using equation (3), compute the voltage at bus 2 with $I_{12}$ (computed in Step 1) and the specified voltage $V_{1 \text { real }}$.

- The previous calculation is repeated until new voltages are determined at the end buses (buses 3 and 4). The voltages at the end buses must be stored to be used in Step 1.

- Repeat Step 1, using the voltages at the end buses computed in Step 2.

Fig. 3 shows a Flow Chart for the Forward and Backward Sweep algorithm, working as a whole.

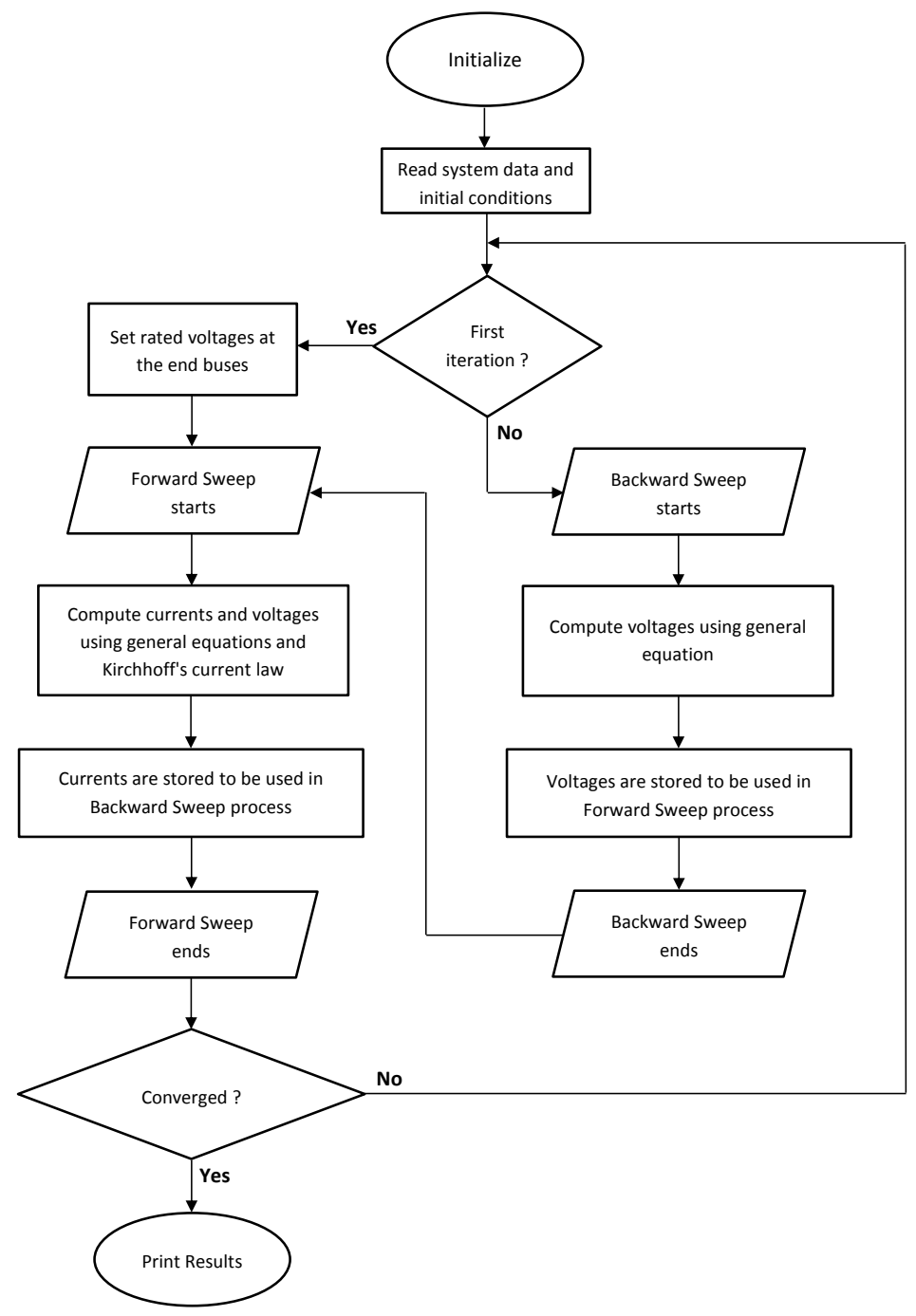

Figure 3: Flow Chart for the Forward and Backward Sweep algorithm.

\section{Problem Formulation}

The optimization problem is described in this section. The reconfiguration is a process to determine the optimal switch status in the entire system. In this paper, the problem is formulated as a multi-objective optimization problem that tries to optimize two objectives satisfying a set of constraints described below.

\subsection{Objective Functions}

\subsubsection{Power Loss Minimization}

The first objective to minimize is the total real power loss of the system. The losses are computed for each phase and each branch of the distribution system. The sum of all branch losses is equal to the total real 
power loss of the system. The mathematical formulation for the minimization of real power loss is presented as

$$
\operatorname{Min}\left\{P_{\text {total }}\right\}=\operatorname{Min}\left\{\sum_{i=1}^{n r} R_{i} \cdot\left|I_{i}\right|^{2}\right\}
$$

where

$P_{\text {total }}=$ total real power loss of the system

$n r=$ number of system branches

$R_{i}=$ resistance of branch $i$

$I_{i}=$ current of branch $i$

\subsubsection{Unbalanced Voltage Minimization}

The second objective function is the unbalanced voltage minimization on the bus with the highest voltage unbalance index in the system. The voltage unbalance index is computed in the literature in different ways. Considering standards used by utilities worldwide, as [32, 33, this paper implements the voltage unbalance factor (VUF) as the voltage unbalance index, which is the ratio between negative-sequence and positive-sequence voltage 34. Therefore, the Unbalanced Voltage Minimization is computed as

$$
\operatorname{Min}\left\{V U F_{\max }\right\}
$$

where

$V U F_{\max }=$ the highest voltage unbalance index of the system.

\subsection{Constraints}

- Voltage constraint: Voltage magnitude at each bus must lie within maximum and minimum allowable limits.

$$
0,93 \text { p.u. } \leqslant V_{i}(\text { p.u. }) \leqslant 1,05 \text { p.u. }, \quad i \epsilon\left(1,2, \ldots, n_{b}\right)
$$

where

$V_{i}=$ voltage of bus $i$

$n_{b}=$ number of buses

p.u. $=$ per unit (adimensional unit commonly used in electrical engineering)

- Current constraint: branch currents should not exceed their maximum current capacities.

$$
I_{j} \leqslant I_{j, \max }, \quad j \in\left(1,2, \ldots, n_{r}\right)
$$

where

$I_{j}=$ current of branch $j$

$I_{j, \max }=$ current capacity of branch $j$

$n_{r}=$ number of system branches

- Topology constraint: The system configuration must be radial and without isolated buses.

\section{Genetic Algorithm in Distribution System Reconfiguration}

Genetic Algorithms are powerful search algorithms and can be used in a wide range of engineering problems. This paper compares two algorithms based on Genetic Algorithm, NSGA-II and GA using the weighted sum method, to solve the Distribution System Reconfiguration problem.

A Genetic Algorithm is a search algorithm based on the mechanisms of natural selection and natural genetics. It combines survival of the fittest among string structures with a structured yet randomized information exchange to form a search algorithm with some of the innovative flair of human search [35. In every generation, a new set of artificial individuals (children) is created, in general, using hits and pieces of the fittest of the individuals (parents); an occasional new part may be tried for exploration. 


\subsection{Genetic Algorithm Parameters}

In order to solve the Distribution System Reconfiguration problem applying either NSGA-II or GA using the weighted sum method, it is necessary to adapt some distribution system characteristics. All parameters and operators used in this paper were selected and calibrated by the authors taking into account their pragmatic experience on reconfiguration problems. Several runs were performed and different methods and operators were tested before choosing the appropriate parameters and operators. Details of the chosen parameters and operators are described below.

\subsubsection{Codification}

The codification adopted in this paper was proposed in [36. The representation of each system topology is carried out using a binary coding, where the chromosomes have fixed length equal to the number of system switches. The binary values indicate the status of each switch, a number "1" indicates a closed switch while the number " 0 " represents an open switch.

Fig. 4 shows a system representation through a chromosome. In Fig. 4a, it can be noted that each system switch is represented by a number, and Fig. $4 \mathrm{~b}$ illustrates the system's chromosome where each switch number corresponds to a locus. The switches 1,4 and 5 are closed, therefore, the locus 1,4 and 5 are filled with number "1". The other system switches are open, for this reason the other locus are filled with number "0". This way, it is possible to represent the system topology with a binary vector.

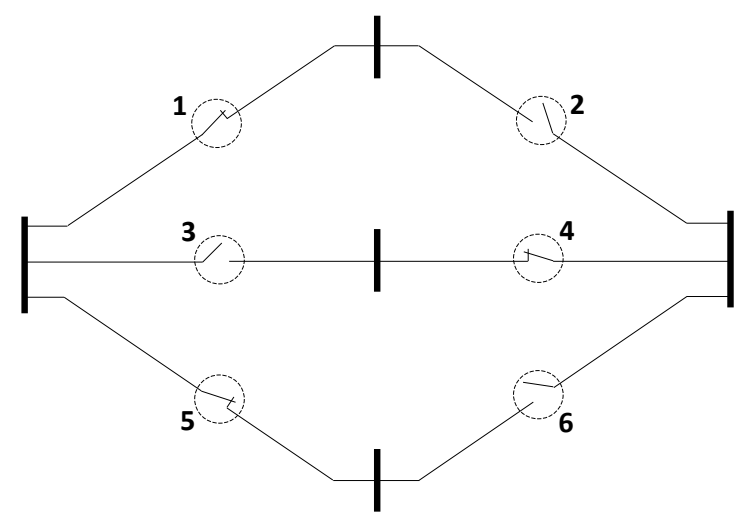

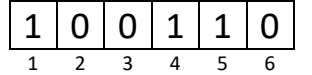

(b) System's chromosome

(a) Six switch system

Figure 4: Codification of a six switch system.

\subsubsection{Initial population}

In this paper, a completely random initial population with 30 individuals is proposed, in order to assure a high genetic diversity at the beginning of the optimization process. Due to the characteristics of the distribution systems, the random population may generate a large number of non-feasible individuals. Therefore, it will be necessary to check the system topology of all individuals, and if it is needed, a topology correction will be performed using the methodology proposed in Section 5

\subsubsection{Fitness Evaluation}

The three-phase power flow algorithm must be run for each individual in order to obtain the real power loss and the voltage unbalance index. Once these parameters are computed for the entire population, it is possible to determine the fitness of each individual.

The proposed two methods to solve the reconfiguration problem are (1) GA using the weighted sum method and (2) NSGA-II. In GA using the weighted sum method (GAWS), the multi-objective problem is adapted into a single objective GA, so the fitness calculation follows the mathematical expression of equation 8):

$$
F=\sum_{i=1}^{k} w_{i} \cdot \frac{f_{i}(x)}{f_{i}\left(x_{0}\right)}
$$

where

$F=$ Unified objective function. 
$f_{i}(x)=$ Objective function $i$.

$f_{i}\left(x_{0}\right)=$ Normalization magnitude.

$w_{i}=$ Weight factor for objective function $i$.

$k=$ Number of objectives.

The weights $w_{i}$ typically satisfy the following condition:

$$
\sum_{i=1}^{k} w_{i}=1
$$

where $w_{i} \geqslant 0, \forall_{i}=1, \ldots, k[37$.

On the other hand, when using NSGA-II, the fitness is assigned to each population member based on non-dominated sorting (Pareto concept) as presented in [20, preserving diversity among solutions of the same non-dominated front.

\subsubsection{Operators}

The Selection operator applied in this paper is the tournament selection; this method is probably the most popular selection method in GA due to its efficiency and simple implementation [38. In the binary tournament selection implemented, 2 individuals are selected randomly from the population, and the selected individuals compete against each other. The individual with the highest fitness wins. The probability that an individual $x$ is selected for the tournament is inversely proportional to the population size $n$, that means it is a uniform probability, which is not based on the fitness quality. The probability is equal to $p(x)=\frac{1}{n}$.

Elitist selection refers to retaining intact the best $n$ individuals $(n \geq 1)$ from the current generation to the next one. In GAWS, the best solution is selected to carry over to the next generation, without any change. On the other hand, when using the NSGA-II it is not necessary to select any individual to apply Elitism, since all previous and current population members are included in the selection for the next generation. In other words, for NSGA-II approach, Elitism is ensured.

The Crossover operator implemented in this work is the single-point method. The single-point crossover uses a common random point (crossover point) in parent chromosomes and then combines the chromosomes at the crossover point to create two children. An example is shown in Fig. 5 this example performs one point crossover for two different topologies of a system and then creates two children. The buses of the left and right ends are source buses, while the other are load buses.

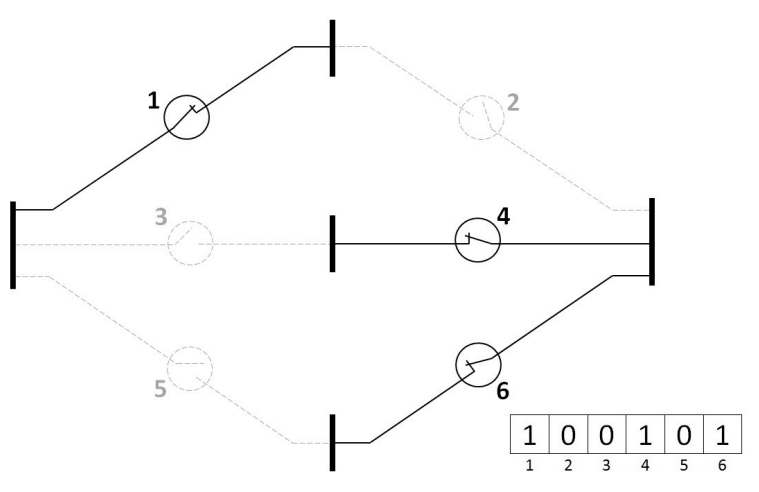

Parent 1

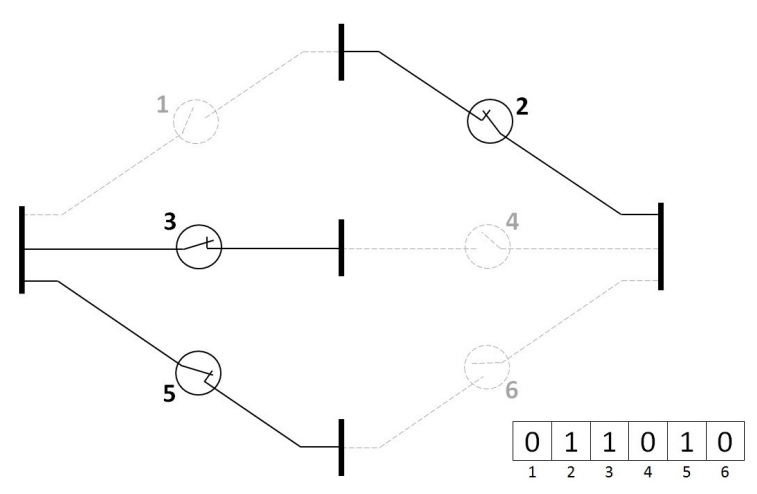

Parent 2

Figure 5: System configurations (Parents).

The crossover process is detailed in Fig. 6, note that the crossover point is 4 . 


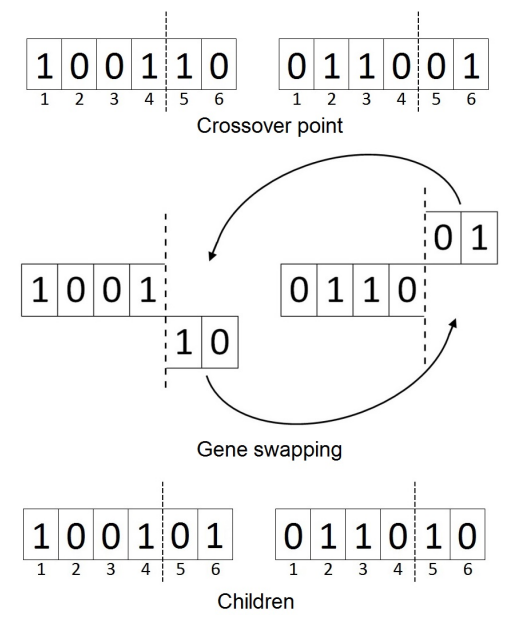

Figure 6: Crossover process.

The two configurations resulting from the crossover process are represented in Fig. 7. both configurations (offsprings) are feasible configurations (radial and without isolated buses) in this short example.
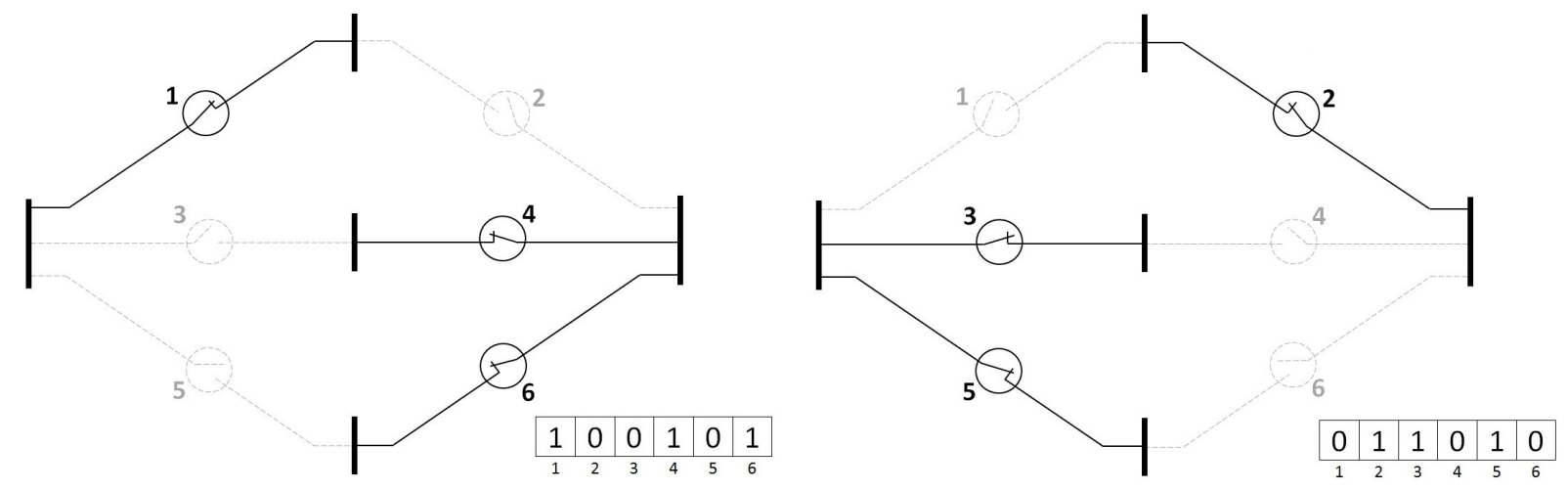

Figure 7: Offsprings from crossover.

The proposed mutation operator randomly selects an individual from the population with a uniform probability, as in the tournament selection. Then, two switches are randomly selected to have their state (on/off) changed. Fig. 8 shows a system configuration where the locus 5 and 6 were randomly selected to be mutated.

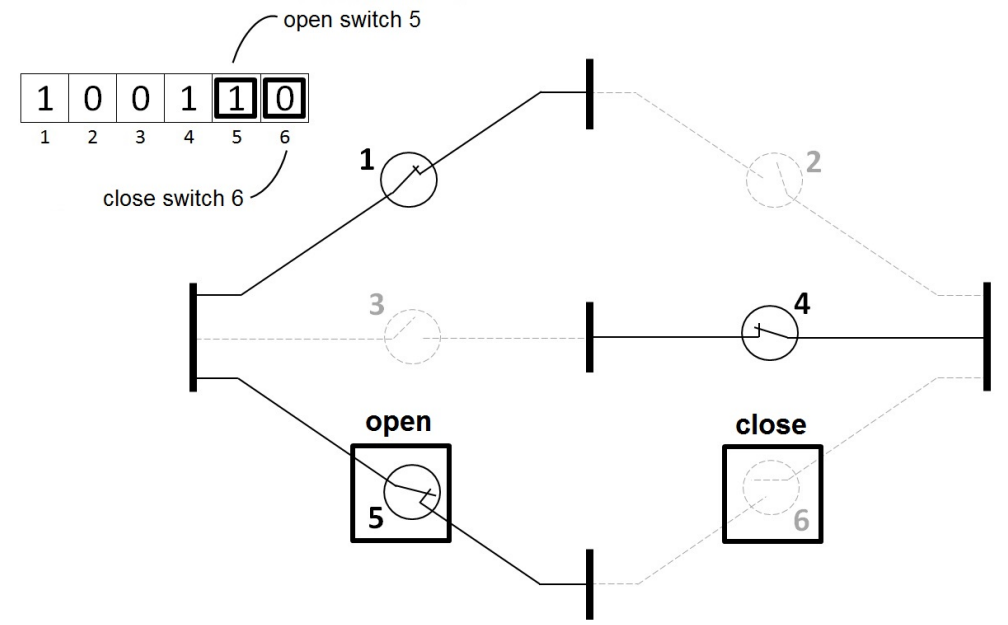

Figure 8: Individual selected for the mutation process.

Fig. 9 represents a feasible configuration resulting from mutation. The mutation and crossover operators change the chromosome, what can generate an infeasible configuration. When an individual coming from a 
mutation process is an infeasible configuration, the topology correction method detailed in Section 5 will be applied, to ensure a radial feasible topology.

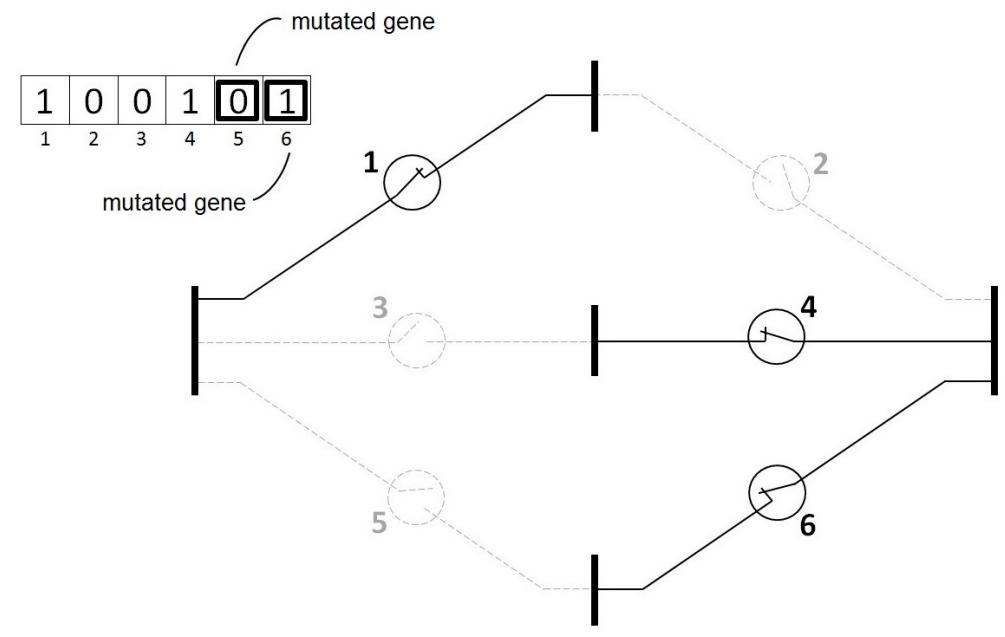

Figure 9: Individual coming from mutation process.

\subsubsection{Stopping Condition}

An a priori fixed number of iterations is the stopping condition implemented. In this approach, the iterations are executed for a maximum number of generations. In the case of GAWS, only the best system configuration, obtained so far, is taken to be the optimal solution. However, in the case of NSGA-II, all system configurations from the Pareto-optimal solutions, obtained in the last generation, are consider as optimal solutions.

\subsection{Multi-objective reconfiguration problem for GAWS}

The proposed GAWS reformulates the multi-objective problem into a single objective problem. In this method, the objective function weights are systematically changing in order to find the Pareto optimal solutions one by one. Ideally, weights of each objective function are assigned by the decision maker based on the intrinsic knowledge of the problem [37.

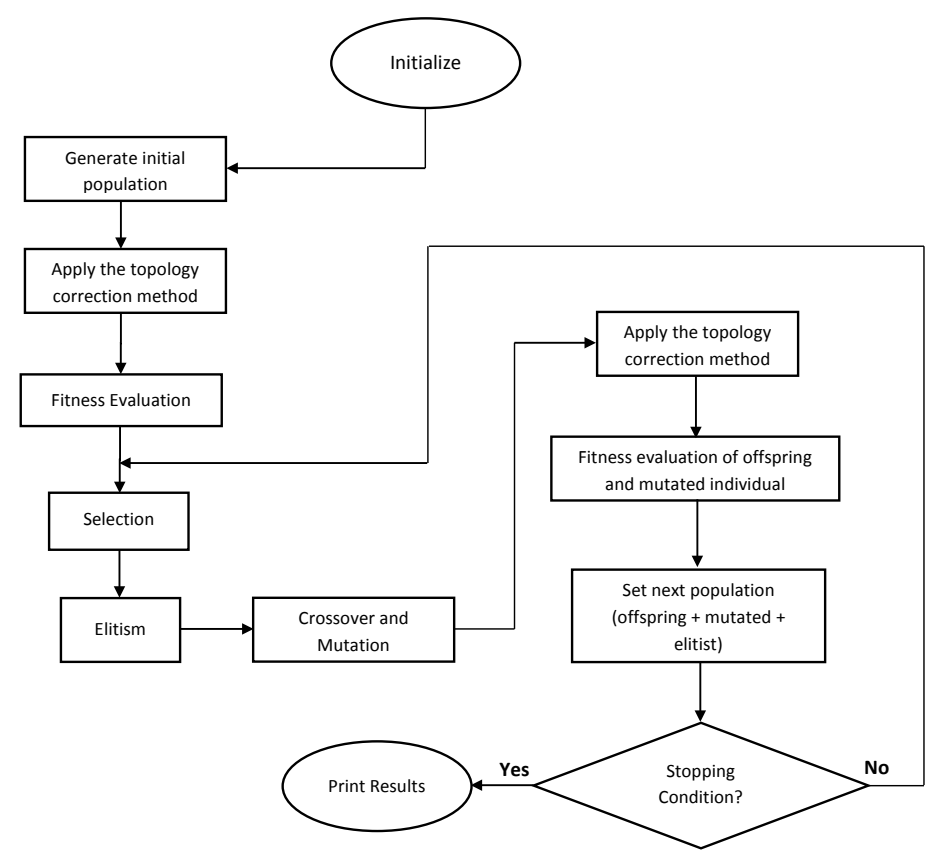

Figure 10: Flow Chart for the GAWS in a reconfiguration problem. 
The proposed reconfiguration problem has two objective functions with different magnitudes, so the normalization of objectives may be useful. The normalization magnitude applied in this paper is equal to the magnitude of the objective function at an initial point $w_{0}$ 37.

In the GAWS, the objective function is unified as shown in equation (8). Once the objective function is unified and the decision maker assigns weights to each objective function, it is possible to run the reconfiguration problem as a single objective GA. Fig. 10 shows a Flow Chart for the implemented GAWS.

\subsection{Multi-objective reconfiguration problem for NSGA-II}

Instead of reformulating the multi-objective problem into a single objective one, which demands applying the algorithm many times, NSGA-II is able to find multiple Pareto-optimal solutions in one single run [20]. Therefore, the reconfiguration problem is also solved using NSGA-II.

In NSGA-II, the population is sorted based on non-domination [21]. Fig. 11] shows the NSGA-II procedure, where $P_{t}$ is the parent population of size $N$ and $Q_{t}$ is the offspring population of size $N$ as well. A fitness is assigned to each solution in base of its non-domination level [20.

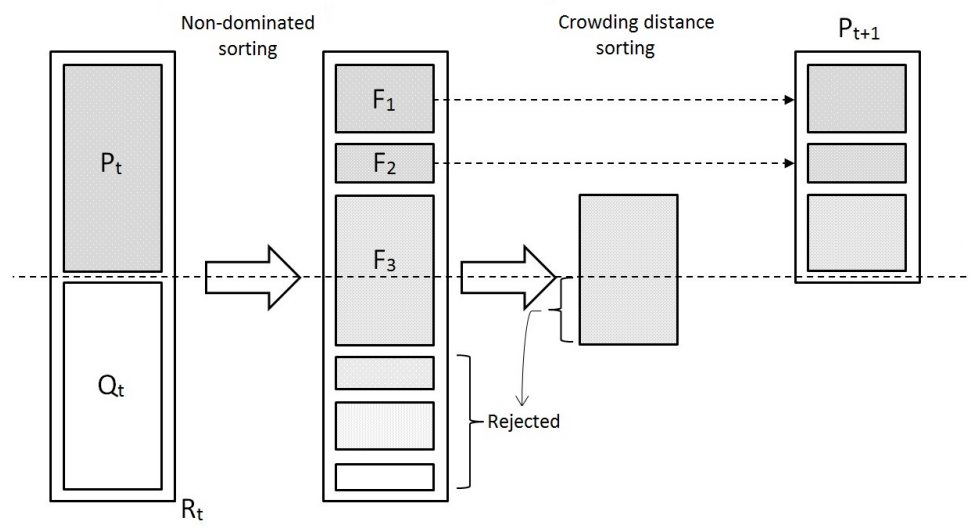

Figure 11: NSGA-II procedure.

Fig. 12 shows a Flow Chart for the multi-objective reconfiguration problem using NSGA-II.

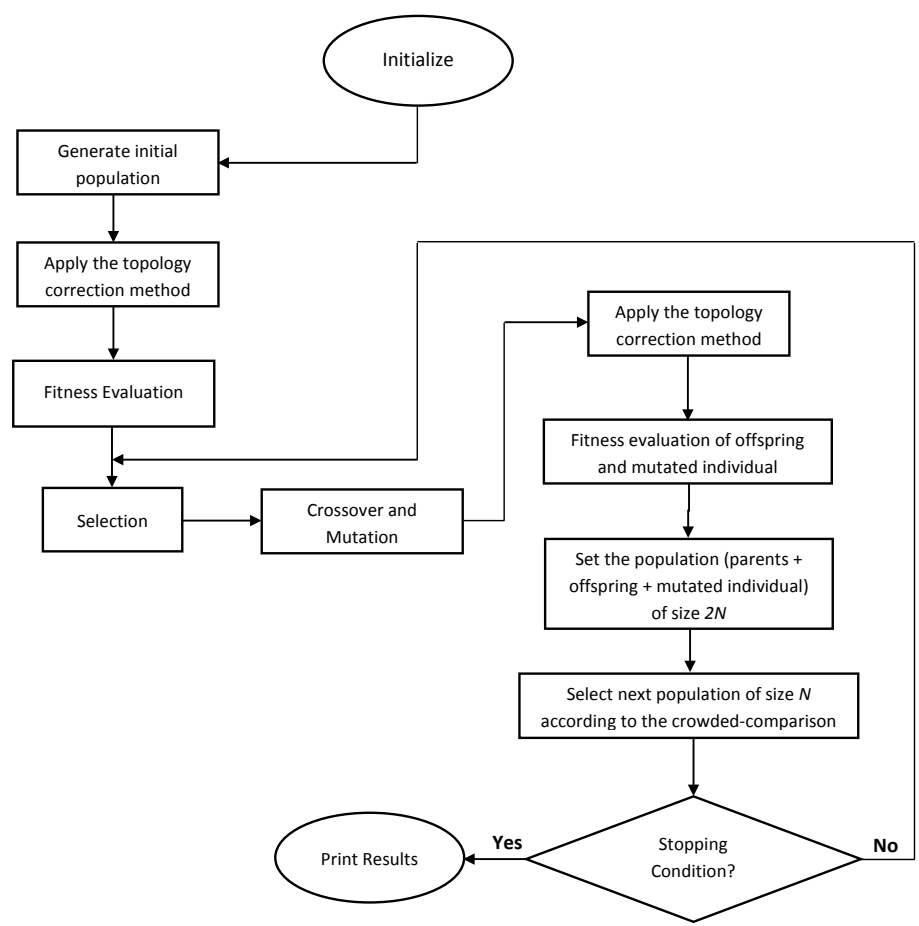

Figure 12: Flow Chart for the multi-objective reconfiguration problem using NSGA-II.

To set exactly $N$ members to the next generation $\left(P_{t+1}\right)$, the solutions of the last front $\left(F_{3}\right.$ in Fig. 11) are 
sorted using the crowded-comparison operator [20. To compute the crowding distance, firstly, the boundary solutions (smallest and largest objective value) of the front are consider as having the best crowding distance of the front. For the other individuals, equation $[10$ is applied to compute every single crowding distance.

$$
d_{i}=\sum_{j=1}^{k} \frac{f_{j}^{(i+1)}-f_{j}^{(i-1)}}{f_{j}^{\max }-f_{j}^{\text {min }}}
$$

Equation $10 p$ represents the crowding distance for solution $i$. The $f_{j}^{(i+1)}$ and $f_{j}^{(i-1)}$ parameters are equal to the objective function values for neighboring solutions $(i+1)$ and $(i-1)$ respectively, and $f_{j}^{\text {max }}$ and $f_{j}^{\text {min }}$ represent the maximum and minimum objective function values for objective function $j$. Parameter $k$ is the number of objective functions.

\subsection{Result Assessment}

When comparing algorithms in a single objective optimization context, it is easy to choose the algorithm that has found the lowest result in minimization problems. However, in a pure multi-objective context where a set of solutions is found by each algorithm, the selection of the best algorithm is not that trivial. Several comparison metrics were defined for this purpose, but the Hypervolume Indicator is by far the most accepted metric in the specialized literature 39. Therefore, this indicator will be used to compare the results achieved by the multi-objective algorithms.

The Hypervolume Indicator proposed in [40, comprises calculating areas (volume, or hypervolume depending on the number of objective functions). Given that this work only considers 2 simultaneous objective functions, it calculates areas between each point of the Pareto Front and a given reference point $(\mathrm{P})$. The assessment is made comparing the areas generated by fronts from different algorithms. To illustrate the concept, Fig. 13 represents a Pareto Front with eight solutions and a reference point $(\mathrm{P})$ indicating the rectangles whose areas should be added to find the desired Hypervolume Indicator.

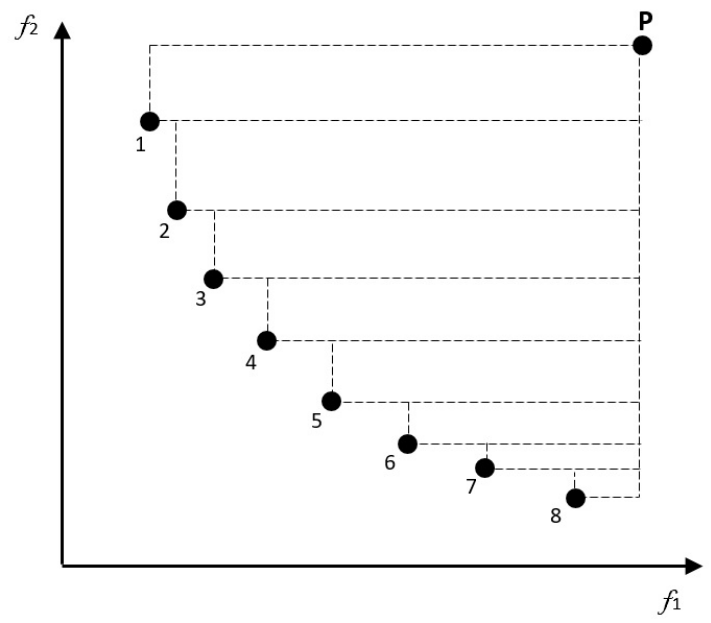

Figure 13: Hypervolume Indicator.

The total area of the rectangles will be equal to the Hypervolume Indicator (HV), equation (11) can be used to compute HV.

$$
H V=\sum_{k=1}^{n} \text { Area }_{k}
$$

where

$H V=$ Hypervolume Indicator

$n=$ number of solutions

Area $_{k}=$ area of solution $k$

\section{Topology correction}

The Minimum-Spanning-Tree technique was chosen to fix infeasible configurations generated by the genetic operators, due to its similarity to the distribution system problem. 
A spanning tree of a graph is a subset of edges forming a tree connecting all vertices [41]. Any tree is the smallest possible connected graph in terms of number of edges, while the Minimum-Spanning-Tree (MST) is the smallest connected graph in terms of edge weight.

To interconnect a set of $n$ vertices, we can use an arrangement of $n-1$ edges, each connecting two vertices. We can model this problem with a connected, undirected graph $G=(V, E)$, where $V$ is the set of vertices, $\mathrm{E}$ is the set of possible interconnections between pairs of vertices, i.e. $(u, v) \epsilon E$. We have a weight $w(u, v)$ specifying the cost to connect $u$ and $v$. We then wish to find an acyclic subset $T \subseteq E$ that connects all the vertices and whose total weight $w(T)=\sum w(u, v)$ is minimized [42. Since $T$ is acyclic and connects all the vertices, it must form a tree, which we call a spanning tree since it spans all nodes of graph $G$. We call the problem of determining the tree $T$ the MST problem. Associating the MST problem with the distribution system reconfiguration problem, it can be noted the relationship between these two problems. In the MST problem, the aim is to obtain an acyclic connected graph that connects all the vertices and whose total weight is minimized. On the other hand, in a distribution system reconfiguration, the problem searches a radial system (no mesh) configuration without isolated buses.

This paper proposes adapting the MST problem in order to fix infeasible configurations. Fig. 14 shows the analogy between a distribution system and a graph.

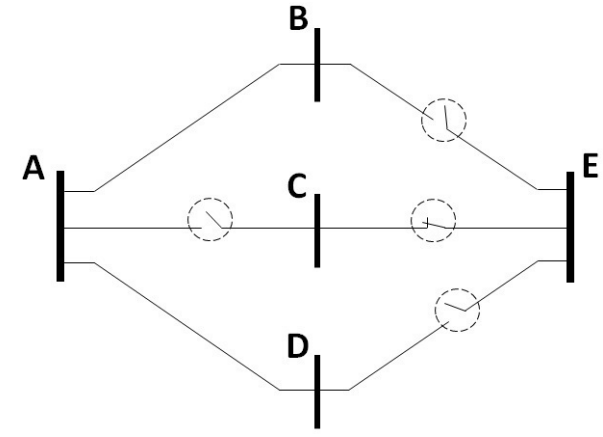

(a) Distribution system single line diagram.

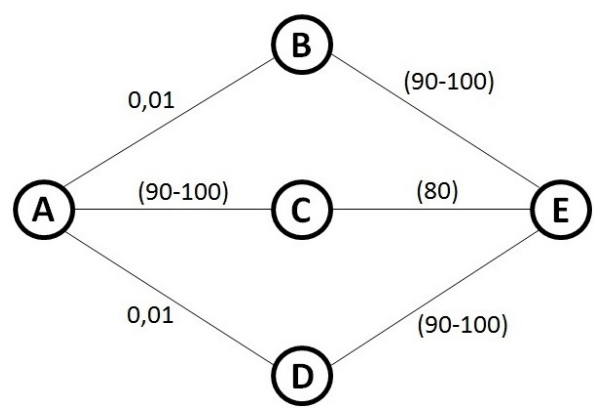

(b) Distribution system graph representation.

Figure 14: Analogy between a distribution system and a graph.

In the graph representation, a weight of 0,01 is set for distribution lines without switches (lines $(A, B)$ and $(A, D))$. For closed switch line $((C, E))$, a weight of 80 is set, and for open switches $((A, C),(B, E)$ and $(D, E))$ a random weight range between 90 and 100 is set. These weights have been set considering that the MST problem seeks the lowest weight path, so the MST will find the solution using all lines without switches and try to follow the original configuration as much as possible, which means giving more probability for not using open switch lines.

In order to increase genetic diversity, we vary the MST path when the same infeasible configuration emerges during the reconfiguration process. Therefore, for open switch lines, a random weight (90-100) is proposed in order to get a variety of configurations.

Since the MST method ensures a topology correction as long as the system has only one source bus, this paper proposes adapting multi source bus systems as a single source bus system; this allows the MST method finding the lowest weight path without forming loops between source buses.

Fig. 15 shows the adaptation of the system shown in Fig. 14, where source buses $A$ and $E$ are joined forming a single bus.

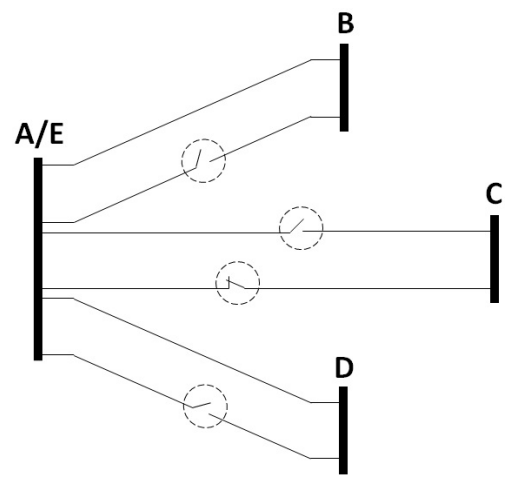

Figure 15: Two source bus system adapted into a single source bus. 
Once the distribution system is converted into a graph, the topology correction becomes a MST problem. Among the algorithms for MST problem, there are two greedy algorithms, the Kruskal [27] and Prim [26] algorithms. Both algorithms are briefly described below.

\subsection{Kruskal and Prim algorithms}

Kruskal's algorithm: In Kruskal's algorithm, the set $T$ represents a forest whose vertices are all vertices of the given graph. The safe edge added to $T$ is always a least-weight edge in the graph that connects two distinct components [42. Kruskal's algorithm qualifies as a greedy algorithm because at each step it adds to the forest an edge of least possible weight. Algorithm 1 shows how Kruskal's algorithm works.

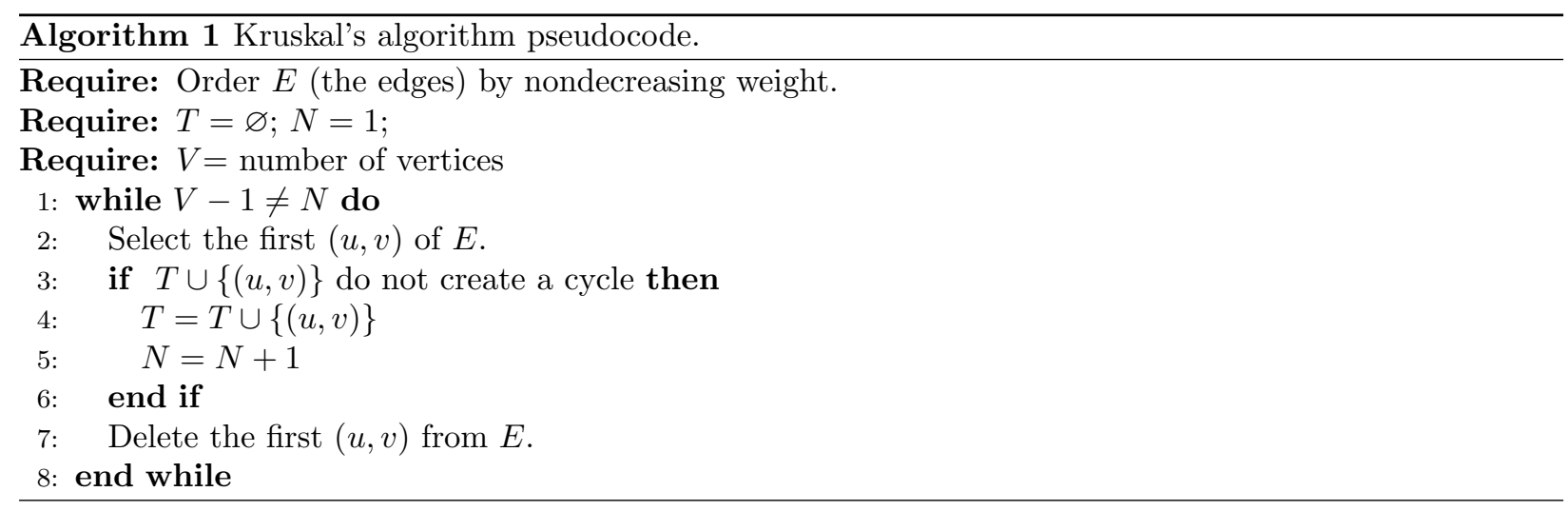

Prim's algorithm: In Prim's algorithm, the set $T$ forms a single tree. The safe edge added to $T$ is always a least-weight edge connecting the tree to a vertex not in the tree 42. This algorithm qualifies as greedy since at each step it adds to the tree an edge that contributes the minimum possible amount to the tree's weight. Algorithm 2 shows the Prim's algorithm pseudocode.

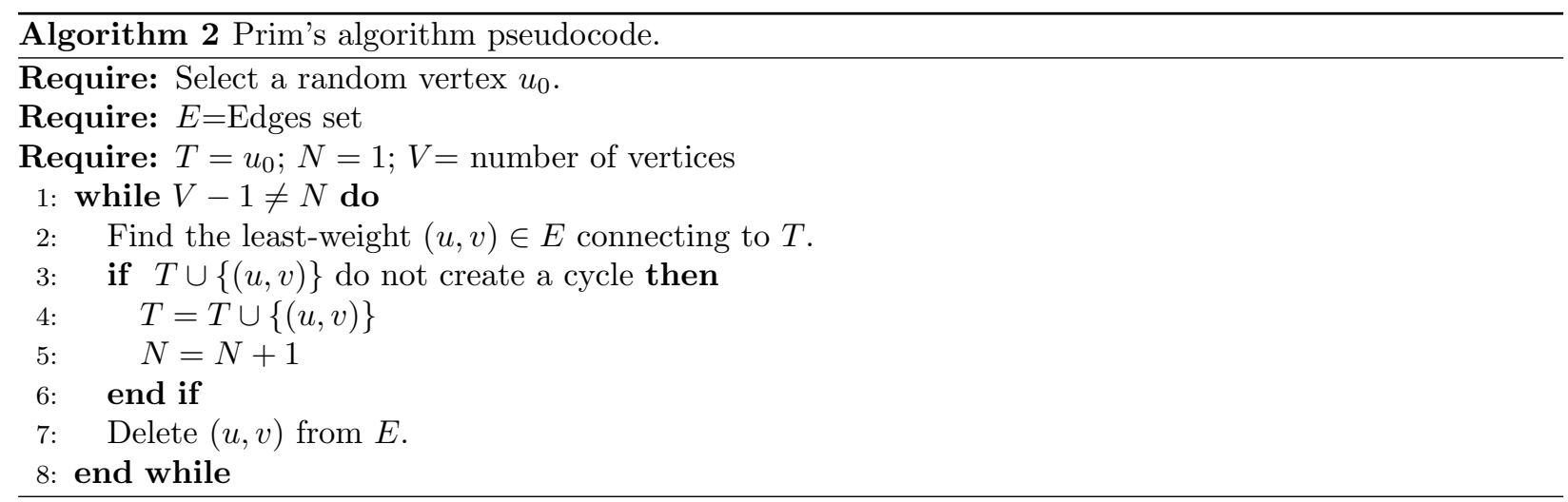

\subsection{Algorithm Comparison}

The Prim's algorithm has an algorithmic complexity of order $O\left(|V|^{2}\right)$ where $|V|$ is the cardinality of the set of vertices $V$. Kruskal's algorithm has an algorithmic complexity of order $O(|E| \log |V|)$ where $|E|$ is the cardinality of the set of edges [43. Consequently, the Prim's algorithm is faster on dense graphs; while Kruskal's is faster on sparse graphs [41].

In distribution system, a dense graph would be a system with many switching possibilities. On the other hand, sparse graph would be a system with just a few switching possibilities. Fig. 16 shows two systems with 5 buses, where one of them forms a sparse graph and the other one a dense graph.

Normally, the distribution system switching possibilities are similar to the sparse case shown in Fig. 16 For this reason, in most cases the Kruskal's algorithm would be more suitable in topology correction problems, but we have to consider that running time of Prim's algorithm can be improved using pairing heaps [41. Pairing heaps are designed to speed up decrease-key operations, where the priority of an item already in the priority queue is reduced. Properly implemented and used, they lead to better performance on very large systems. 


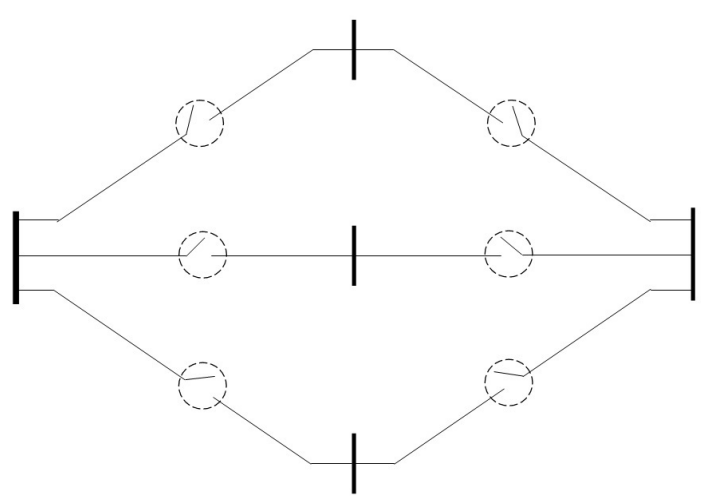

Distribution system forming a sparse graph.

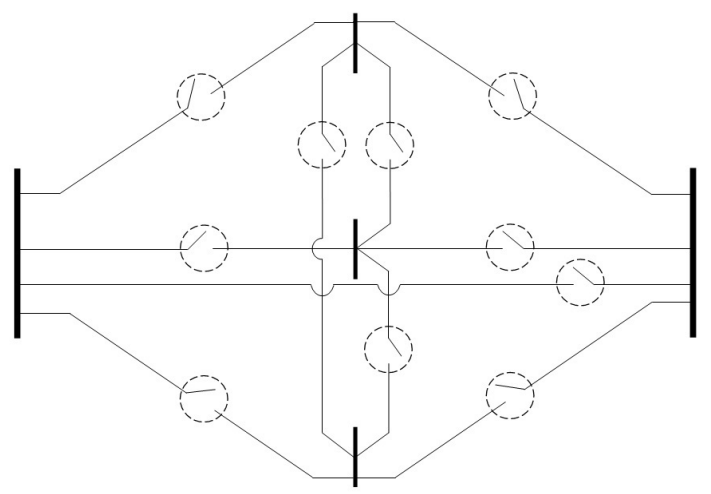

Distribution system forming a dense graph.

Figure 16: Sparse and dense graphs for distribution system.

Using pairing heaps, Prim's algorithm can be improved, which makes Prim's implementation using pairing heaps the practical choice for both sparse and dense graphs [41. Hence, the improved version of Prim's algorithm is chosen to fix infeasible configurations generated by genetic operators.

\section{Study Cases}

In this section, the reconfiguration algorithm is tested on an example of distribution system, comparing the results with previous work where a single objective is minimized. Moreover, the two proposed reconfiguration algorithms (GAWS and NSGA-II) are applied on unbalanced distribution systems minimizing two objective functions. All algorithms were developed in Matlab and implemented on a $2.4 \mathrm{GHz}$ PC with $8 \mathrm{~GB}$ of RAM.

\subsection{Validation of the Proposed Algorithm}

The proposed reconfiguration algorithm is tested in the well-known 16-bus system (see Fig. 17) presented in 4. The buses are labeled with numbers, while the switches with letters. The system has 13 load buses and 3 source buses (substations), with 16 switches. The system data is shown in Table 1 .

Considering that the system was originally solved as a single objective problem (Power Loss Minimization), the first test is performed using the proposed reconfiguration algorithm to minimize only the system losses. The primary aim of this first test is to validate the proposed reconfiguration algorithm - which includes GA, Three-Phase Power Flow and Topology Correction algorithms - comparing the proposed algorithm results with 44 results.

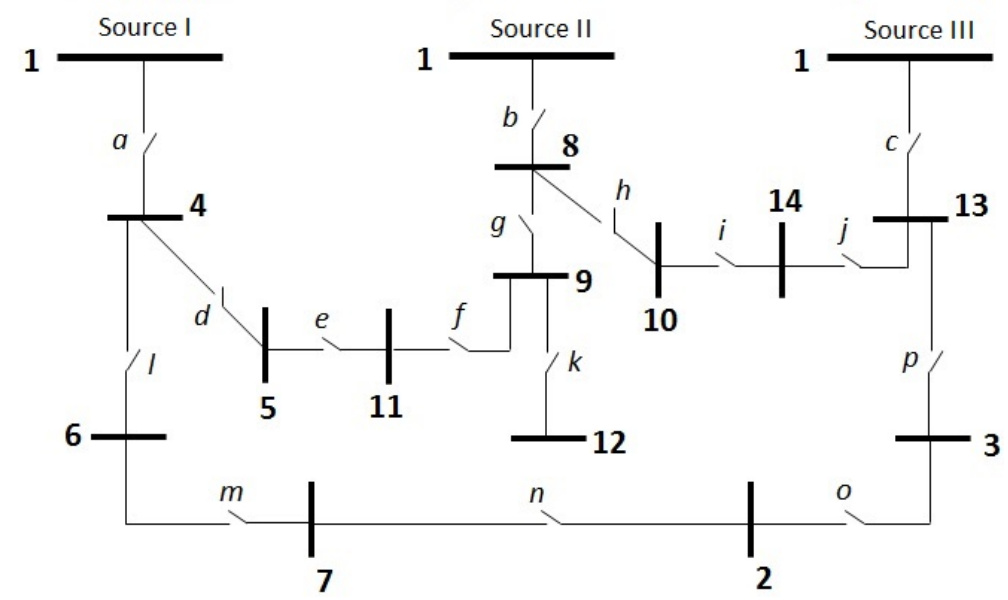

Figure 17: 16-bus system. 
Table 1: Data of the example system.

\begin{tabular}{|c|c|c|c|}
\hline \multicolumn{2}{|c|}{ Bus } & \multirow{2}{*}{$\begin{array}{l}\text { Impedance of } \\
\text { line A-B (pu) }\end{array}$} & \multirow{2}{*}{$\begin{array}{c}\text { Load of Bus B } \\
(\mathrm{kVA})\end{array}$} \\
\hline $\mathbf{A}$ & B & & \\
\hline 1 & 4 & $0.075+0.1 \mathrm{i}$ & $2000+1600 \mathrm{i}$ \\
\hline 4 & 5 & $0.08+0.11 \mathrm{i}$ & $3000+400 \mathrm{i}$ \\
\hline 4 & 6 & $0.09+0.18 \mathrm{i}$ & $2000-400 \mathrm{i}$ \\
\hline 6 & 7 & $0.04+0.04 \mathrm{i}$ & $1500+1200 \mathrm{i}$ \\
\hline 1 & 8 & $0.11+0.11 \mathrm{i}$ & $4000+2700 \mathrm{i}$ \\
\hline 8 & 9 & $0.08+0.11 \mathrm{i}$ & $5000+1800 \mathrm{i}$ \\
\hline 8 & 10 & $0.11+0.11 \mathrm{i}$ & $1000+900 \mathrm{i}$ \\
\hline 11 & 9 & $0.11+0.11 \mathrm{i}$ & $5000+1800 \mathrm{i}$ \\
\hline 9 & 12 & $0.08+0.11 \mathrm{i}$ & $4500-1700 \mathrm{i}$ \\
\hline 1 & 13 & $0.11+0.11 \mathrm{i}$ & $1000+900 \mathrm{i}$ \\
\hline 13 & 14 & $0.09+0.12 \mathrm{i}$ & $1000-1100 \mathrm{i}$ \\
\hline 13 & 3 & $0.08+0.11 \mathrm{i}$ & $1000+900 \mathrm{i}$ \\
\hline 3 & 2 & $0.04+0.04 \mathrm{i}$ & $2100-800 \mathrm{i}$ \\
\hline 5 & 11 & $0.04+0.04 \mathrm{i}$ & $600-500 \mathrm{i}$ \\
\hline 10 & 14 & $0.04+0.04 \mathrm{i}$ & $1000-1100 \mathrm{i}$ \\
\hline 7 & 2 & $0.09+0.12 \mathrm{i}$ & 2100-800i \\
\hline
\end{tabular}
2

The algorithm is executed 40 times, and different numbers of generations are used, as depicted in Table

Table 2: Results achieved using different numbers of generations.

\begin{tabular}{ccccc}
\hline Execution & 10_Generations & 20_Generations & 50_Generations & 100_Generations \\
\hline 1 & $466.1 \mathrm{~kW}$ & $466.1 \mathrm{~kW}$ & $466.1 \mathrm{~kW}$ & $466.1 \mathrm{~kW}$ \\
2 & $466.1 \mathrm{~kW}$ & $466.1 \mathrm{~kW}$ & $466.1 \mathrm{~kW}$ & $466.1 \mathrm{~kW}$ \\
3 & $479.3 \mathrm{~kW} *$ & $466.1 \mathrm{~kW}$ & $466.1 \mathrm{~kW}$ & $466.1 \mathrm{~kW}$ \\
4 & $479.3 \mathrm{~kW} *$ & $466.1 \mathrm{~kW}$ & $466.1 \mathrm{~kW}$ & $466.1 \mathrm{~kW}$ \\
5 & $466.1 \mathrm{~kW}$ & $466.1 \mathrm{~kW}$ & $466.1 \mathrm{~kW}$ & $466.1 \mathrm{~kW}$ \\
6 & $466.1 \mathrm{~kW}$ & $466.1 \mathrm{~kW}$ & $466.1 \mathrm{~kW}$ & $466.1 \mathrm{~kW}$ \\
7 & $483.9 \mathrm{~kW}$ & $466.1 \mathrm{~kW}$ & $466.1 \mathrm{~kW}$ & $466.1 \mathrm{~kW}$ \\
8 & $479.3 \mathrm{~kW}$ & $466.1 \mathrm{~kW}$ & $466.1 \mathrm{~kW}$ & $466.1 \mathrm{~kW}$ \\
9 & $479.3 \mathrm{~kW}$ & $466.1 \mathrm{~kW}$ & $466.1 \mathrm{~kW}$ & $466.1 \mathrm{~kW}$ \\
10 & $466.1 \mathrm{~kW}$ & $479.3 \mathrm{~kW}$ & $466.1 \mathrm{~kW}$ & $466.1 \mathrm{~kW}$ \\
\hline Average run-time & $2.53 \mathrm{sec}$ & $4.32 \mathrm{sec}$ & $9.36 \mathrm{sec}$ & $17.10 \mathrm{sec}$ \\
\hline
\end{tabular}

Comparing the proposed algorithm results with the optimal result $(466.1 \mathrm{~kW})$ from [44, the algorithm fails 5 times for 10 Generations in 10 executions, and once for 20 Generations in 10 executions. On the other hand, the algorithm does not fails either for 50 or for 100 Generations. Hence, it can be inferred from the results that the proposed reconfiguration algorithm works well when the number of generations is large enough.

Given that 100 generations has high probability to find the optimal configuration, a maximum number of generations equal to 100 will be used in the next simulations on this system.

\subsection{Unbalanced distribution system}

Table 3: Unbalanced load data.

\begin{tabular}{ccccc}
\hline \multirow{2}{*}{ Bus } & $\mathrm{A}$ & 0 & Load per phase(kVA) & Load Type \\
\hline 1 & 0 & $\mathrm{~B}$ & 0 & Feeder \\
2 & $(1200-1300 \mathrm{i}) / 3$ & $(1200-1800 \mathrm{i}) / 3$ & $(1100-1200 \mathrm{i}) / 3$ & I cte. $-\Delta$ \\
3 & $(2600-100 \mathrm{i}) / 3$ & $(2300-10 \mathrm{i}) / 3$ & $(2500-200 \mathrm{i}) / 3$ & PQ $-\Delta$ \\
4 & $(2800+1700 \mathrm{i}) / 3$ & $(2200+1500 \mathrm{i}) / 3$ & $(3000+1800 \mathrm{i}) / 3$ & $\mathrm{PQ}-\mathrm{Y}$ \\
5 & $(2000+1200 \mathrm{i}) / 3$ & $(2200+1100 \mathrm{i}) / 3$ & $(2300+1300 \mathrm{i}) / 3$ & $\mathrm{PQ}-\mathrm{Y}$ \\
6 & $(3000-600 \mathrm{i}) / 3$ & $(3500-10 \mathrm{i}) / 3$ & $(3200-800 \mathrm{i}) / 3$ & PQ $-\Delta$ \\
7 & $(2600+2600 \mathrm{i}) / 3$ & $(2600+2200 \mathrm{i}) / 3$ & $(3100+3100 \mathrm{i}) / 3$ & I cte. $-\mathrm{Y}$ \\
8 & $(4200+2000 \mathrm{i}) / 3$ & $(4000+200 \mathrm{i}) / 3$ & $(4000+100 \mathrm{i}) / 3$ & $\mathrm{Z}$ cte. $-\mathrm{Y}$ \\
9 & $(1800-1400 \mathrm{i}) / 3$ & $(1700-1470 \mathrm{i}) / 3$ & $(1750-1480 \mathrm{i}) / 3$ & I cte. $-\mathrm{Y}$ \\
10 & $(3500+2500 \mathrm{i}) / 3$ & $(3400+2400 \mathrm{i}) / 3$ & $(3300+2290 \mathrm{i}) / 3$ & $\mathrm{Z}$ cte. $-\mathrm{Y}$ \\
11 & $(1300+1300 \mathrm{i}) / 3$ & $(1500+1100 \mathrm{i}) / 3$ & $(1300+1150 \mathrm{i}) / 3$ & $\mathrm{Z}$ cte. $-\Delta$ \\
12 & $(2000-1000 \mathrm{i}) / 3$ & $(2500-2700 \mathrm{i}) / 3$ & $(2500-3700 \mathrm{i}) / 3$ & I cte. $-\Delta$ \\
13 & $(2200+700 \mathrm{i}) / 3$ & $(2100+1000 \mathrm{i}) / 3$ & $(3000+1000 \mathrm{i}) / 3$ & PQ - Y \\
14 & $(4100+1000 \mathrm{i}) / 3$ & $(4300+1200 \mathrm{i}) / 3$ & $(4000+1200 \mathrm{i}) / 3$ & Z cte. $-\Delta$ \\
\hline
\end{tabular}


In order to obtain an unbalanced system similar to a real distribution system, the system loads were modified given that the original system loads are balanced. The unbalanced loads are shown in Table 3 . The other system parameters remains the same.

\subsubsection{Application of GAWS}

GAWS is applied in the reconfiguration problem as shown in equation 12 .

$$
\operatorname{Min} \quad F=w_{1} \cdot f_{1}(x)+w_{2} \cdot f_{2}(x)
$$

where

$$
\begin{gathered}
f_{1}(x)=P_{\text {total }} \\
f_{2}(x)=V U F_{\max }
\end{gathered}
$$

Based on the aforementioned normalization method, the proposed reconfiguration algorithm is applied using the initial points $w_{1}=0.5$ and $w_{2}=0.5$. The CPU time used by the proposed method is around 35 seconds (s), the experimental results are:

$P_{\text {total }}=543.5 \mathrm{~kW}$

$V U F_{\max }=0.3964 \%$

Table 4 presents various optimized solutions for 11 different weights. Ten runs were executed for each weight and the same outcome was found, due to space limitations, the table displays the outcomes only once. The CPU time used to obtain each result was approximately the same $(35 \mathrm{~s})$.

Table 4: Different weights tested.

\begin{tabular}{ccc}
\hline Weights & $P_{\text {total }}(k W)$ & $V U F_{\max }(\%)$ \\
\hline$w_{1}=0.01 ; w_{2}=0.99$ & 729.75 & 0.3484 \\
$w_{1}=0.10 ; w_{2}=0.90$ & 729.75 & 0.3484 \\
$w_{1}=0.20 ; w_{2}=0.80$ & 627.07 & 0.358 \\
$w_{1}=0.30 ; w_{2}=0.70$ & 627.07 & 0.358 \\
$w_{1}=0.40 ; w_{2}=0.60$ & 546.08 & 0.3949 \\
$w_{1}=0.50 ; w_{2}=0.50$ & 543.5 & 0.3964 \\
$w_{1}=0.60 ; w_{2}=0.40$ & 543.5 & 0.3964 \\
$w_{1}=0.70 ; w_{2}=0.30$ & 543.5 & 0.3964 \\
$w_{1}=0.80 ; w_{2}=0.20$ & 543.5 & 0.3964 \\
$w_{1}=0.90 ; w_{2}=0.10$ & 543.5 & 0.3964 \\
$w_{1}=0.99 ; w_{2}=0.01$ & 543.5 & 0.3964 \\
\hline
\end{tabular}

The open switches, the magnitudes of the total real power loss and the highest voltage unbalance index in the system are detailed in Table 5 .

Table 5: Solutions for GAWS.

\begin{tabular}{lcccc}
\hline Open switches & $n-d-j$ & $o-d-h$ & $o-f-i$ & $o-e-i$ \\
\hline$P_{T O T A L}(\mathrm{~kW})$ & 729,75 & 627,07 & 546,08 & 543,5 \\
\hline$V U F_{M A X}(\%)$ & 0,3484 & 0,358 & 0,3949 & 0,3964 \\
\hline
\end{tabular}

Fig. 18 shows the Pareto front obtained from GAWS.

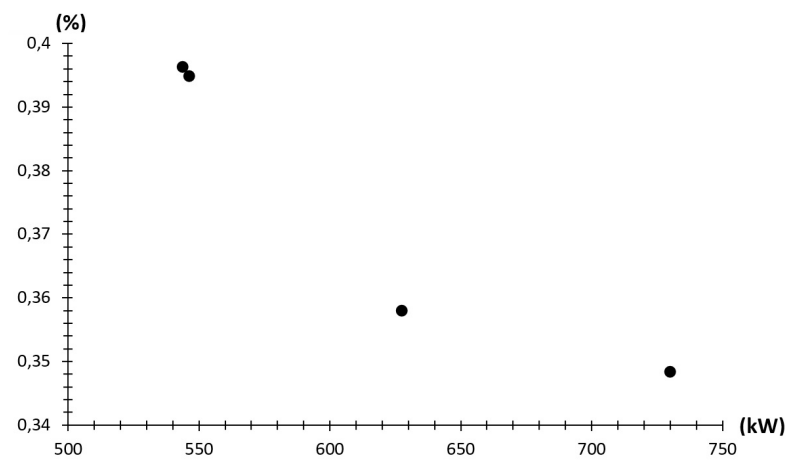

Figure 18: Pareto front for GAWS. 


\subsubsection{Application of NSGA-II}

NSGA-II algorithm is also applied to the same example. The Pareto-optimal solutions achieved by this algorithm in ten different runs were identical. For brevity, Table 6 details the Pareto-optimal solutions just once.

Table 6: Solutions for NSGA-II algorithm.

\begin{tabular}{cccccccc}
\hline \multirow{2}{*}{$\begin{array}{c}\text { PARETO F. } \\
\text { (non-dominated) })\end{array}$} & Open switches & $n-d-j$ & $o-d-h$ & $o-f-h$ & $o-h-e$ & $o-f-i$ & $o-e-i$ \\
\cline { 2 - 8 } & $P_{T O T A L}(\mathrm{~kW})$ & 729,75 & 627,07 & 607,45 & 589,77 & 546,08 & 543,5 \\
\cline { 2 - 7 } & $V U F_{M A X}(\%)$ & 0,3484 & 0,358 & 0,3816 & 0,3832 & 0,3949 & 0,3964 \\
\hline
\end{tabular}

Note that the NSGA-II achieved six optimal solutions, two more than GAWS. The CPU time used by the NSGA-II algorithm is $1 \mathrm{~min} 19 \mathrm{~s}$. Fig. 19 shows the Pareto front obtained by the NSGA-II algorithm.

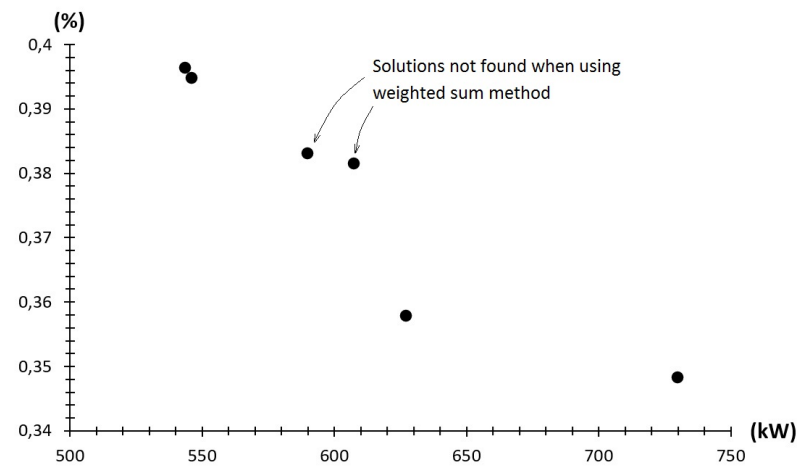

Figure 19: Pareto front for NSGA-II.

\subsection{Extended distribution system}

To evaluate the proposed algorithms on a larger system, the unbalanced system is extended, interconnecting the same system 5 times, as shown in Fig. 20. The new system has 66 buses, 9 sources and 80 switches.

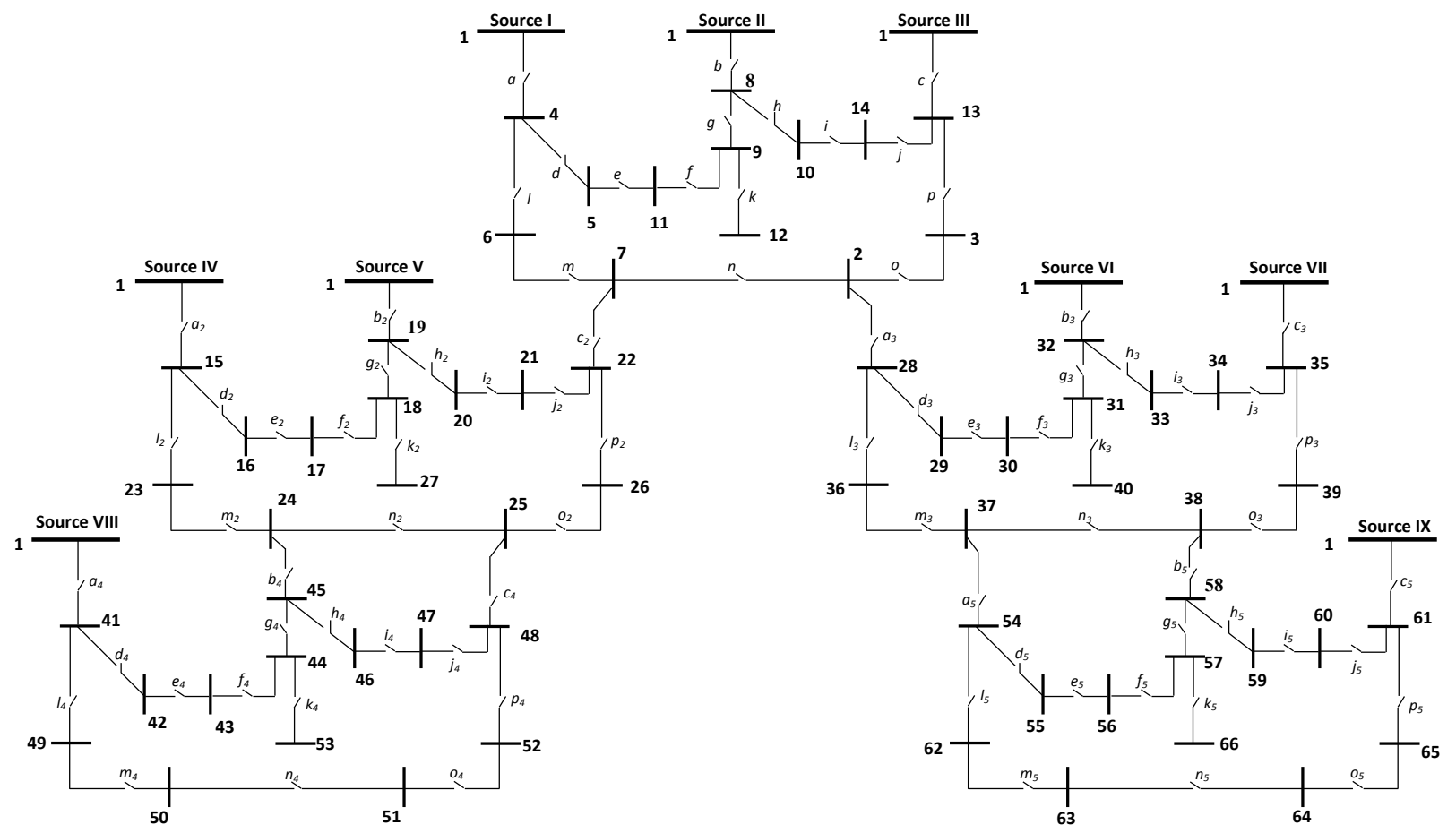

Figure 20: 66-bus system. 


\subsubsection{GAWS for the 66-bus system}

GAWS is applied on the new 66-bus system. Eleven algorithm runs are performed through 100 generations using 11 different weight combinations in order to find each Pareto front. The weight combinations are the same used in Section 6.2.1. The average time for each run (one weight combination) is $4 \mathrm{~min} 17 \mathrm{~s}$, remembering that each Pareto front was found using 11 weight combinations, finding a Pareto front with GAWS (for 100 generations) took approximately $47 \mathrm{~min} 7 \mathrm{~s}$. The process was executed 10 times, Fig. 21 depicts the Pareto fronts found by GAWS, and Table 7 shows the magnitudes of each Pareto front.

Table 7: Pareto fronts' magnitudes found by GAWS (for 100 generations).

\begin{tabular}{|c|c|c|c|c|c|c|c|c|}
\hline \multirow{2}{*}{$\begin{array}{l}1^{s t} 11 \text {-RUNNINGS } \\
\text { PARETO FRONT }\end{array}$} & $P_{\text {TOTAL }}(\mathrm{kW})$ & 5712,2 & 6328,4 & 7105,8 & - & - & - & - \\
\hline & $V U F_{M A X}(\%)$ & 0,785 & 0,7085 & 0,6002 & - & - & - & - \\
\hline \multirow{2}{*}{$\begin{array}{c}2^{n d} 11 \text {-RUNNINGS } \\
\text { PARETO FRONT }\end{array}$} & $P_{\text {TOTAL }}(\mathrm{kW})$ & 5996,7 & 6187,7 & 6512,2 & 6951,6 & - & - & - \\
\hline & $V U F_{M A X}(\%)$ & 0,785 & 0,7471 & 0,6776 & 0,5742 & - & - & - \\
\hline \multirow{2}{*}{$\begin{array}{l}3^{r d} 11-R U N N I N G S \\
\text { PARETO FRONT }\end{array}$} & $P_{\text {TOTAL }}(\mathrm{kW})$ & 5937,9 & 6015,1 & 6069,8 & 6125,4 & 6736,3 & 7122,3 & 7861,3 \\
\hline & $V U F_{M A X}(\%)$ & 0,8106 & 0,785 & 0,7471 & 0,746 & 0,6584 & 0,6052 & 0,5914 \\
\hline \multirow{2}{*}{$\begin{array}{l}4^{t h} 11 \text {-RUNNINGS } \\
\text { PARETO FRONT }\end{array}$} & $P_{\text {TOTAL }}(\mathrm{kW})$ & 6102,3 & 6401,3 & 6468,4 & 7078,4 & - & - & - \\
\hline & $V U F_{M A X}(\%)$ & 0,8101 & 0,7263 & 0,6998 & 0,5742 & - & - & - \\
\hline \multirow{2}{*}{$\begin{array}{l}5^{t h} 11 \text {-RUNNINGS } \\
\text { PARETO FRONT }\end{array}$} & $P_{\text {TOTAL }}(\mathrm{kW})$ & 5793,2 & 6138 & 6501 & 6934,9 & - & - & - \\
\hline & $V U F_{M A X}(\%)$ & 0,7783 & 0,7471 & 0,7165 & 0,5848 & - & - & - \\
\hline \multirow{2}{*}{$\begin{array}{l}6^{t h} 11-R U N N I N G S \\
\text { PARETO FRONT }\end{array}$} & $P_{\text {TOTAL }}(\mathrm{kW})$ & 5903 & 6005 & 6063,7 & 6103,1 & 6642,5 & 6766,9 & - \\
\hline & $V U F_{M A X}(\%)$ & 0,8649 & 0,7773 & 0,7768 & 0,7471 & 0,6002 & 0,5742 & - \\
\hline \multirow{2}{*}{$\begin{array}{l}7^{t h} \text { 11-RUNNINGS } \\
\text { PARETO FRONT }\end{array}$} & $P_{\text {TOTAL }}(\mathrm{kW})$ & 5934 & 6397,7 & 6975,3 & - & - & - & - \\
\hline & $V U F_{M A X}(\%)$ & $\begin{array}{l}0,7471 \\
\end{array}$ & 0,7164 & 0,5742 & - & - & - & - \\
\hline \multirow{2}{*}{$\begin{array}{l}8^{t h} 11-R U N N I N G S \\
\text { PARETO FRONT }\end{array}$} & $P_{\text {TOTAL }}(\mathrm{kW})$ & 5947,5 & 6476,6 & 7070,9 & - & - & - & - \\
\hline & $V U F_{M A X}(\%)$ & 0,7471 & 0,6584 & 0,5742 & - & - & - & - \\
\hline \multirow{2}{*}{$\begin{array}{l}9^{t h} 11 \text {-RUNNINGS } \\
\text { PARETO FRONT }\end{array}$} & $P_{\text {TOTAL }}(\mathrm{kW})$ & 5974,9 & 6166,3 & 6279,6 & 8801,3 & - & - & - \\
\hline & $V U F_{M A X}(\%)$ & 0,7768 & 0,7471 & 0,7386 & 0,5914 & - & - & - \\
\hline \multirow{2}{*}{$\begin{array}{c}10^{t h} 11 \text {-RUNNINGS } \\
\text { PARETO FRONT }\end{array}$} & $P_{\text {TOTAL }}(\mathrm{kW})$ & 5719,6 & 5992,1 & 7334,2 & - & - & - & - \\
\hline & $V U F_{M A X}(\%)$ & 0,7848 & 0,7471 & 0,6734 & - & - & - & - \\
\hline
\end{tabular}

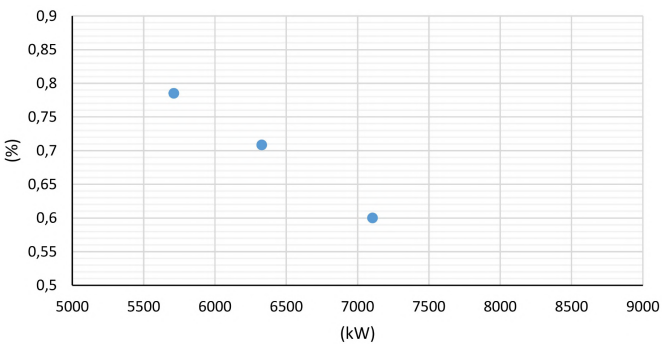

(a) Pareto Front from $1^{\text {st }}$ 11-runnings.

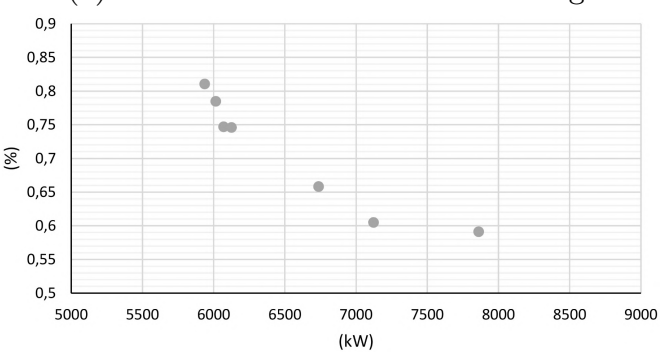

(c) Pareto Front from $3^{\text {rd }}$ 11-runnings.

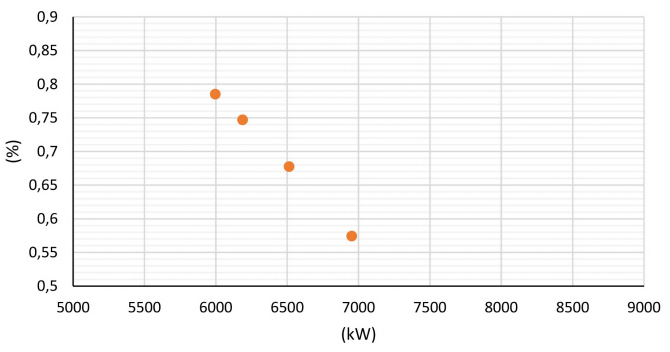

(b) Pareto Front from $2^{\text {nd }}$ 11-runnings.

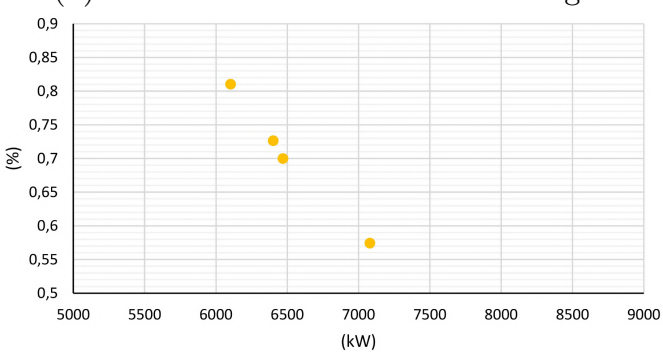

(d) Pareto Front from $4^{\text {th }}$ 11-runnings.

Figure 21: Pareto fronts achieved by GAWS (for 100 generations). 


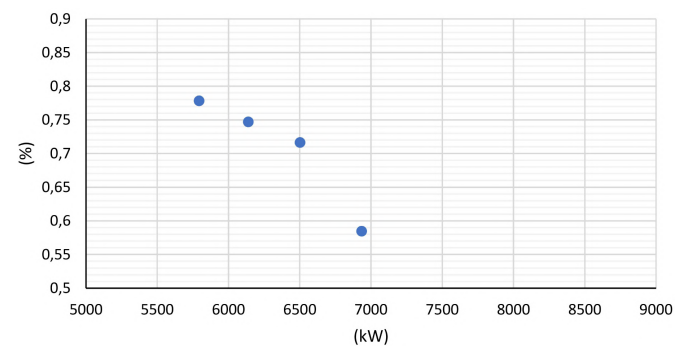

(e) Pareto Front from $5^{\text {th }}$ 11-runnings.

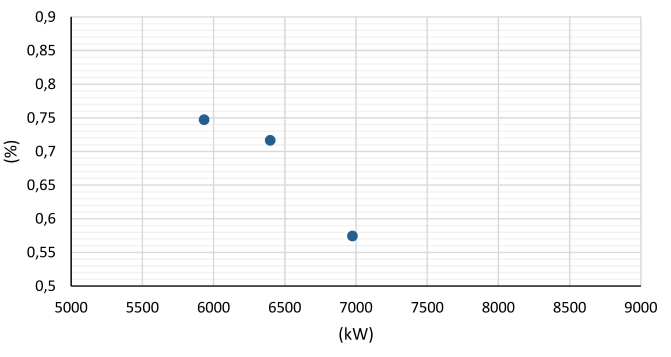

(g) Pareto Front from $7^{\text {th }}$ 11-runnings.

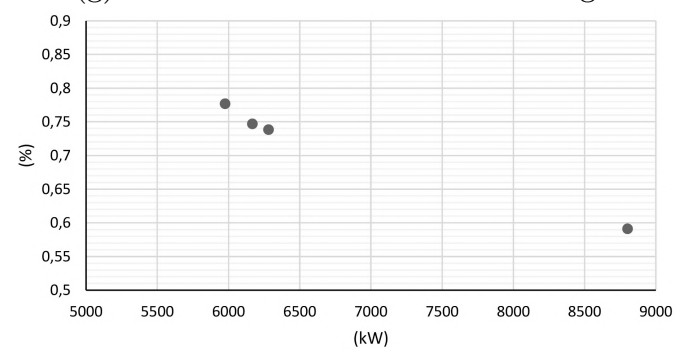

(i) Pareto Front from $9^{\text {th }}$ 11-runnings.

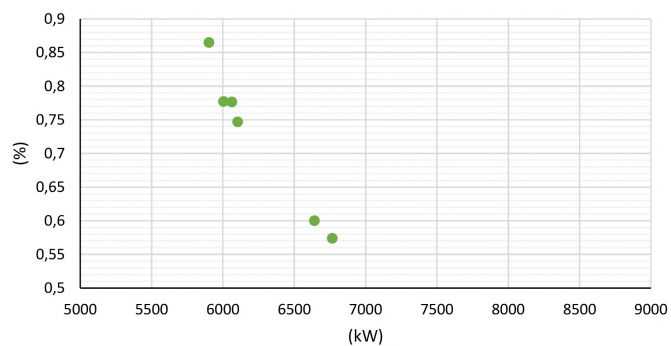

(f) Pareto Front from $6^{\text {th }}$ 11-runnings.

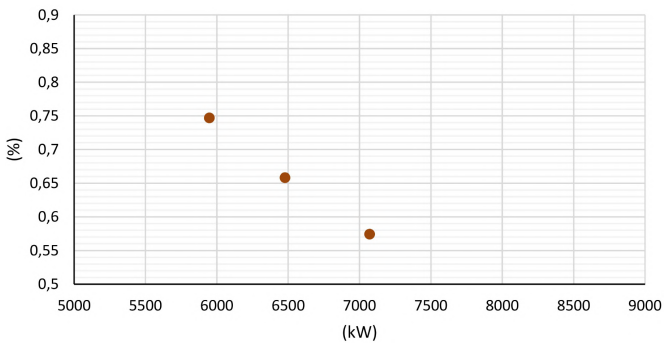

(h) Pareto Front from $8^{\text {th }}$ 11-runnings.

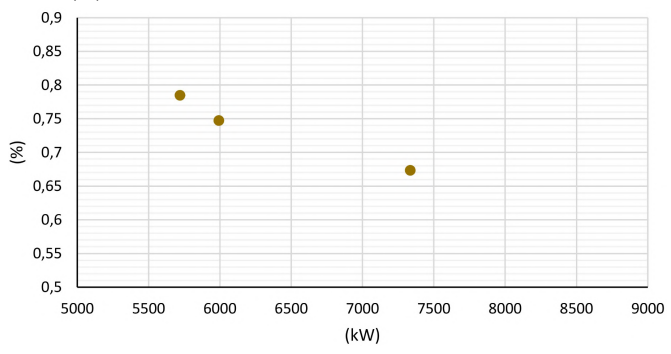

(j) Pareto Front from $10^{\text {th }}$ 11-runnings.

Figure 21: Pareto fronts achieved by GAWS (for 100 generations).

Fig. 22 shows the superimposed results of the 10 Pareto fronts achieved. In 22a each color represents a specific front. On the other hand, in Fig. $22 \mathrm{~b}$ the 11 darker results are the best solutions out of the 41 solutions found throughout the 10 Pareto fronts.

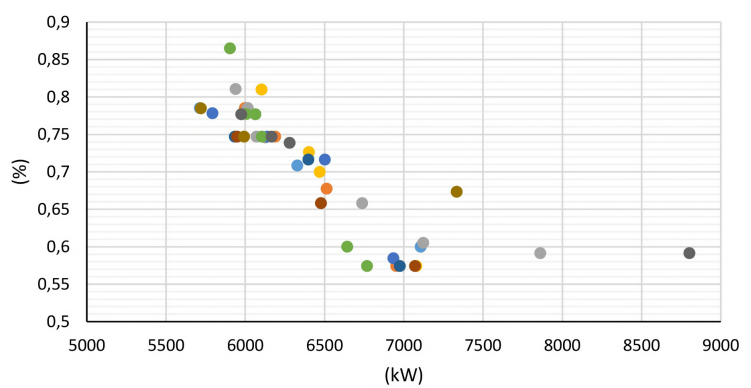

(a) 10 fronts achieved.

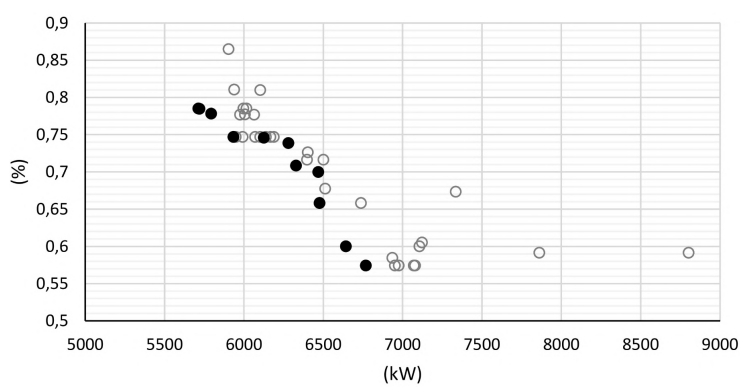

(b) Best solutions identified.

Figure 22: Superimposed results of GAWS (for 100 generations).

It is interesting to note that all 41 solutions in the 10 Pareto fronts are different; this occurs due to the huge variety of possible configurations $\left(2^{80}\right)$. In large distribution systems like this one, there is always a possibility of finding better solutions. Therefore, GAWS is applied 10 times again; the number of generations is increased to 200 in order to have more chances of achieving better results.

The average time for each run (one weight combination) through 200 generations is $9 \mathrm{~min} 05 \mathrm{~s}$, finding a Pareto front took approximately $1 \mathrm{~h} 39 \mathrm{~min} 55 \mathrm{~s}$. The process was executed 10 times, Table 8 shows the magnitudes of the 10 Pareto fronts achieved. It is noted that the results were improved when compared to the 100 generations case. 
Table 8: Pareto fronts' magnitudes found by GAWS (for 200 generations).

\begin{tabular}{|c|c|c|c|c|c|c|}
\hline \multirow{2}{*}{$\begin{array}{l}1^{\text {st }} 11 \text {-RUNNINGS } \\
\text { PARETO FRONT }\end{array}$} & $P_{\text {TOTAL }}(\mathrm{kW})$ & 5887 & 6324,9 & 6486,9 & 6877,3 & - \\
\hline & $V U F_{M A X}(\%)$ & 0,7773 & 0,7165 & 0,6928 & 0,5742 & - \\
\hline \multirow{2}{*}{$\begin{array}{c}2^{n d} 11-\text { RUNNINGS } \\
\text { PARETO FRONT }\end{array}$} & $P_{\text {TOTAL }}(\mathrm{kW})$ & 5697 & 5899,9 & 6209 & 6538,1 & 6821 \\
\hline & $V U F_{M A X}(\%)$ & 0,7471 & 0,7366 & 0,6975 & 0,5946 & 0,5742 \\
\hline \multirow{2}{*}{$\begin{array}{l}3^{r d} 11-R U N N I N G S \\
\text { PARETO FRONT }\end{array}$} & $P_{\text {TOTAL }}(\mathrm{kW})$ & 5603,9 & 6181,6 & 6847,3 & - & - \\
\hline & $V U F_{M A X}(\%)$ & 0,7773 & 0,7471 & 0,5742 & - & - \\
\hline \multirow{2}{*}{$\begin{array}{l}4^{t h} 11-R U N N I N G S \\
\text { PARETO FRONT }\end{array}$} & $P_{\text {TOTAL }}(\mathrm{kW})$ & 5788,9 & 6127,1 & 6422,5 & 7222,6 & 8004,3 \\
\hline & $V U F_{M A X}(\%)$ & 0,7471 & 0,7164 & 0,6801 & 0,6734 & 0,6052 \\
\hline \multirow{2}{*}{$\begin{array}{l}5^{t h} \text { 11-RUNNINGS } \\
\text { PARETO FRONT }\end{array}$} & $P_{\text {TOTAL }}(\mathrm{kW})$ & 5584,3 & 5969 & 6651,4 & 6829,1 & - \\
\hline & $V U F_{M A X}(\%)$ & 0,8754 & 0,7164 & 0,6002 & 0,5742 & - \\
\hline \multirow{2}{*}{$\begin{array}{l}6^{t h} 11-\text { RUNNINGS } \\
\text { PARETO FRONT }\end{array}$} & $L(\mathrm{~kW})$ & 5765,4 & 5899,9 & 6978,1 & - & - \\
\hline & $V U F_{M A X}(\%)$ & 0,785 & 0,7366 & 0,5742 & - & - \\
\hline \multirow{2}{*}{$\begin{array}{l}7^{t h} \text { 11-RUNNINGS } \\
\text { PARETO FRONT }\end{array}$} & $P_{\text {TOTAL }}(\mathrm{kW})$ & 5789,4 & 5969 & 6218,9 & 6747,2 & - \\
\hline & $V U F_{M A X}(\%)$ & 0,7471 & 0,7164 & 0,6975 & 0,5742 & - \\
\hline \multirow{2}{*}{$\begin{array}{l}8^{t h} 11 \text {-RUNNINGS } \\
\text { PARETO FRONT }\end{array}$} & $P_{\text {TOTAL }}(\mathrm{kW})$ & 5580,9 & 5997,4 & 6079,8 & 6422,3 & 6761,5 \\
\hline & $V U F_{M A X}(\%)$ & 0,785 & 0,7848 & 0,7471 & 0,7085 & 0,5742 \\
\hline \multirow{2}{*}{$\begin{array}{l}9^{t h} 11-R U N N I N G S \\
\text { PARETO FRONT }\end{array}$} & $P_{\text {TOTAL }}(\mathrm{kW})$ & 5920,3 & 5935,3 & 5969 & 6675,1 & - \\
\hline & $V U F_{M A X}(\%)$ & 0,8818 & 0,8125 & 0,7164 & 0,5742 & - \\
\hline \multirow{2}{*}{$\begin{array}{c}10^{t h} \text { 11-RUNNINGS } \\
\text { PARETO FRONT }\end{array}$} & $P_{\text {TOTAL }}(\mathrm{kW})$ & 5879,4 & 6129,7 & 6637,8 & 6721,4 & - \\
\hline & $V U F_{M A X}(\%)$ & 0,7848 & 0,7164 & 0,6734 & 0,5742 & - \\
\hline
\end{tabular}

All Pareto fronts are depicted in Fig. 23, each color of Fig. 23a represents a specific front. As in the previous study (100 generations case), the 10 Pareto fronts, all together, have 41 solutions. These 41 results have 5 repeated solutions, the 9 darker results of Fig. 23b are the best solutions out of the 41 solutions.

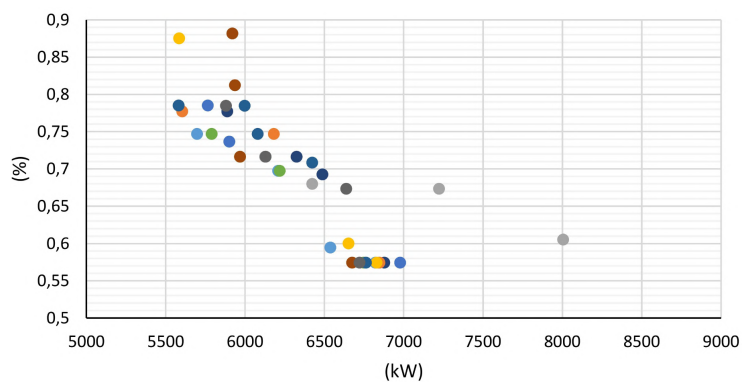

(a) 10 fronts achieved.

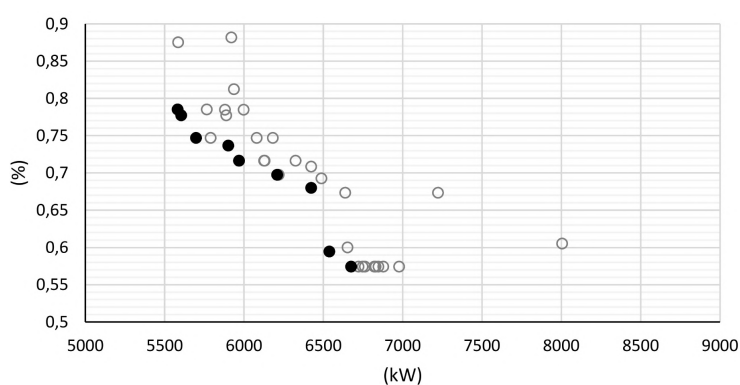

(b) Best solutions identified.

Figure 23: Superimposed results of GAWS (for 200 generations).

\subsubsection{NSGA-II for the 66-bus system}

NSGA-II is also applied on the new 66-bus system. Firstly, 10 independent runs are performed for 100 generations, and secondly, the same number of simulations are executed for 200 generations.

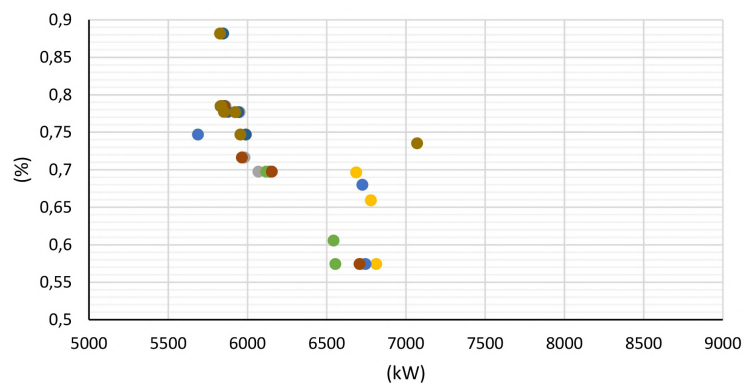

(a) 10 fronts achieved

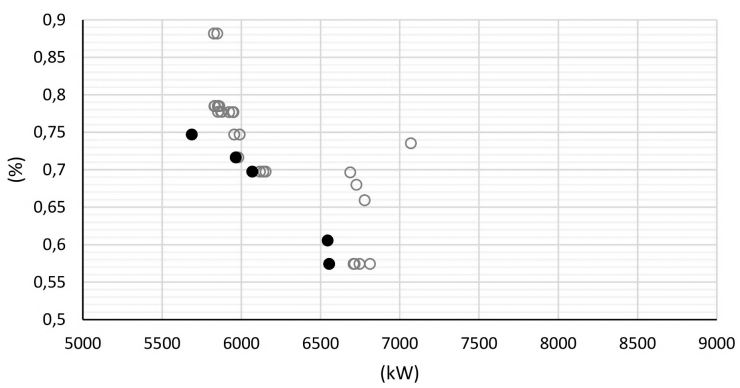

(b) Best solutions identified.

Figure 24: Superimposed results of NSGA-II (for 100 generations).

Table 9 shows the magnitudes of the 10 Pareto fronts for 100 generations; the average time for each run is $7 \mathrm{~min} 32 \mathrm{~s}$. The algorithm found 26 repeated solutions out of the 48 solutions achieved in the 10 Pareto fronts. 
The 10 Pareto fronts achieved for 100 generations are shown in Fig. 24, each color of Fig. 24a represents a different front. The 5 darker results of Fig. 24b represent the best solutions of the fronts.

Table 9: Pareto fronts' magnitudes found by NSGA-II (for 100 generations).

\begin{tabular}{|c|c|c|c|c|c|c|c|}
\hline \multirow{2}{*}{$\begin{array}{c}1^{\text {st }} \text { RUNNING } \\
\text { PARETO FRONT }\end{array}$} & $P_{\text {TOTAL }}(\mathrm{kW})$ & 5860,6 & 5873 & 5964,3 & 6138,6 & 6707,4 & - \\
\hline & $V U F_{M A X}(\%)$ & 0,7848 & 0,7773 & 0,7164 & 0,6975 & 0,5742 & - \\
\hline \multirow{2}{*}{$\begin{array}{c}2^{t h} \text { RUNNING } \\
\text { PARETO FRONT }\end{array}$} & $P_{\text {TOTAL }}(\mathrm{kW})$ & 5860,6 & 5877,6 & 5947,7 & 5989,5 & - & - \\
\hline & $V U F_{M A X}(\%)$ & 0,7848 & 0,7773 & 0,7768 & 0,7471 & - & - \\
\hline \multirow{2}{*}{$\begin{array}{c}3^{r d} \text { RUNNING } \\
\text { PARETO FRONT }\end{array}$} & $P_{\text {TOTAL }}(\mathrm{kW})$ & 5858 & 5950,3 & 5980,8 & 6068,6 & 6714,7 & - \\
\hline & $V U F_{M A X}(\%)$ & 0,7848 & 0,7768 & 0,7164 & 0,6975 & 0,5742 & - \\
\hline \multirow{2}{*}{$\begin{array}{c}4^{t h} \text { RUNNING } \\
\text { PARETO FRONT }\end{array}$} & $P_{\text {TOTAL }}(\mathrm{kW})$ & 5829,8 & 6117,7 & 6686,5 & 6777,8 & 6811,8 & - \\
\hline & $V U F_{M A X}(\%)$ & 0,7848 & 0,6975 & 0,6964 & 0,6594 & 0,5742 & - \\
\hline \multirow{2}{*}{$\begin{array}{c}5^{t h} \text { RUNNING } \\
\text { PARETO FRONT }\end{array}$} & $P_{\text {TOTAL }}(\mathrm{kW})$ & 5687,1 & 5964,3 & 6138,6 & 6725 & 6744,9 & - \\
\hline & $V U F_{M A X}(\%)$ & 0,7471 & 0,7164 & 0,6975 & 0,6801 & 0,5742 & - \\
\hline \multirow{2}{*}{$\begin{array}{c}6^{t h} \text { RUNNING } \\
\text { PARETO FRONT }\end{array}$} & $P_{\text {TOTAL }}(\mathrm{kW})$ & 5829,8 & 6117,7 & 6543,6 & 6554,4 & - & - \\
\hline & $V U F_{M A X}(\%)$ & 0,7848 & 0,6975 & 0,6056 & 0,5742 & - & - \\
\hline \multirow{2}{*}{$\begin{array}{c}7^{t h} \text { RUNNING } \\
\text { PARETO FRONT }\end{array}$} & $P_{\text {TOTAL }}(\mathrm{kW})$ & 5847,2 & 5854,7 & 5873 & 5943,1 & 5989,5 & - \\
\hline & $V U F_{M A X}(\%)$ & 0,8818 & 0,785 & 0,7773 & 0,7768 & 0,7471 & - \\
\hline \multirow{2}{*}{$\begin{array}{c}8^{t h} \text { RUNNING } \\
\text { PARETO FRONT }\end{array}$} & $P_{\text {TOTAL }}(\mathrm{kW})$ & 5850,7 & 5964,3 & 6153,4 & 6707,4 & - & - \\
\hline & $V U F_{M A X}(\%)$ & 0,7848 & 0,7164 & 0,6975 & 0,5742 & - & - \\
\hline \multirow{2}{*}{$\begin{array}{c}9^{t h} \text { RUNNING } \\
\text { PARETO FRONT }\end{array}$} & $P_{\text {TOTAL }}(\mathrm{kW})$ & 5826,4 & 5829,8 & 5852,1 & 5922,2 & 5955,3 & - \\
\hline & $V U F_{M A X}(\%)$ & 0,8818 & 0,7848 & 0,7773 & 0,7768 & 0,7471 & - \\
\hline \multirow{2}{*}{$\begin{array}{c}10^{t h} \text { RUNNING } \\
\text { PARETO FRONT }\end{array}$} & $P_{\text {TOTAL }}(\mathrm{kW})$ & 5826,4 & 5833,9 & 5852,1 & 5922,2 & 5955,3 & 7070,3 \\
\hline & $V U F_{M A X}(\%)$ & 0,8818 & 0,785 & 0,7773 & 0,7768 & 0,7471 & 0,7352 \\
\hline
\end{tabular}

Table 10 shows the magnitudes of the 10 Pareto fronts for 200 generations; the average time for each run is $15 \mathrm{~min} 48 \mathrm{~s}$. The algorithm found 46 repeated solutions out of the 66 solutions achieved with the 10 Pareto fronts.

Table 10: Pareto fronts' magnitudes found by NSGA-II (for 200 generations).

\begin{tabular}{|c|c|c|c|c|c|c|c|c|c|c|}
\hline \multirow{2}{*}{$\begin{array}{c}1^{s t} \text { RUNNING } \\
\text { PARETO FRONT }\end{array}$} & $P_{T O T A L}(\mathrm{~kW})$ & 5548,1 & 5570,5 & 5640,6 & 5661,7 & 5836,1 & 6404,9 & 6481,9 & - & - \\
\hline & $V U F_{M A X}(\%)$ & 0,7848 & 0,7773 & 0,7768 & 0,7164 & 0,6975 & 0,6002 & 0,5742 & - & - \\
\hline \multirow{2}{*}{$\begin{array}{c}2^{\text {nd }} \text { RUNNING } \\
\text { PARETO FRONT }\end{array}$} & $P_{T O T A L}(\mathrm{~kW})$ & 5548,1 & 5661,7 & 5836,1 & 6110 & 6324,8 & 6404,9 & 6481,9 & - & - \\
\hline & $V U F_{M A X}(\%)$ & 0,7848 & 0,7164 & 0,6975 & 0,6776 & 0,6584 & 0,6002 & 0,5742 & - & - \\
\hline \multirow{2}{*}{$\begin{array}{c}3^{r d} \text { RUNNING } \\
\text { PARETO FRONT }\end{array}$} & $P_{T O T A L}(\mathrm{~kW})$ & 5829,8 & 5922,2 & 5943,4 & 6117,7 & 6686,5 & 6721,4 & - & - & - \\
\hline & $V U F_{M A X}(\%)$ & 0,7848 & 0,7768 & 0,7164 & 0,6975 & 0,6964 & 0,5742 & - & - & - \\
\hline \multirow{2}{*}{$\begin{array}{c}4^{t h} \text { RUNNING } \\
\text { PARETO FRONT }\end{array}$} & $P_{\text {TOTAL }}(\mathrm{kW})$ & 5850,7 & 5964,3 & 6138,6 & 6707,4 & - & - & - & - & - \\
\hline & $V U F_{M A X}(\%)$ & 0,7848 & 0,7164 & 0,6975 & 0,5742 & - & - & - & - & - \\
\hline \multirow{2}{*}{$\begin{array}{c}5^{t h} \text { RUNNING } \\
\text { PARETO FRONT }\end{array}$} & $P_{\text {TOTAL }}(\mathrm{kW})$ & 5548,1 & 5570,5 & 5640,6 & 5661,7 & 5836,1 & 6110 & 6324,8 & 6404,9 & 6481,9 \\
\hline & $V U F_{M A X}(\%)$ & 0,7848 & 0,7773 & 0,7768 & 0,7164 & 0,6975 & 0,6776 & 0,6584 & 0,6002 & 0,5742 \\
\hline \multirow{2}{*}{$\begin{array}{c}6^{t h} \text { RUNNING } \\
\text { PARETO FRONT }\end{array}$} & $P_{\text {TOTAL }}(\mathrm{kW})$ & 5829,8 & 5852,1 & 5913,1 & 6391,7 & 6401,8 & 6714,7 & - & - & - \\
\hline & $V U F_{M A X}(\%)$ & 0,7848 & 0,7773 & 0,6975 & 0,6964 & 0,6584 & 0,5742 & - & - & - \\
\hline \multirow{2}{*}{$\begin{array}{c}7^{t h} \text { RUNNING } \\
\text { PARETO FRONT } \\
\end{array}$} & $P_{\text {TOTAL }}(\mathrm{kW})$ & 5548,1 & 5570,5 & 5640,6 & 5661,7 & 5836,1 & 6404,9 & 6481,9 & - & - \\
\hline & $V U F_{M A X}(\%)$ & 0,7848 & 0,7773 & 0,7768 & 0,7164 & 0,6975 & 0,6002 & 0,5742 & - & - \\
\hline \multirow{2}{*}{$\begin{array}{c}8^{t h} \text { RUNNING } \\
\text { PARETO FRONT }\end{array}$} & $P_{T O T A L}(\mathrm{~kW})$ & 5847,2 & 5850,7 & 5873 & 5943,1 & 5964,3 & 6138,6 & 6707,4 & - & - \\
\hline & $V U F_{M A X}(\%)$ & 0,8818 & 0,7848 & 0,7773 & 0,7768 & 0,7164 & 0,6975 & 0,5742 & - & - \\
\hline \multirow{2}{*}{$\begin{array}{c}9^{t h} \text { RUNNING } \\
\text { PARETO FRONT }\end{array}$} & $P_{\text {TOTAL }}(\mathrm{kW})$ & 5544,7 & 5552,3 & 5570,5 & 5640,6 & 5676,3 & 6121 & - & - & - \\
\hline & $V U F_{M A X}(\%)$ & 0,8818 & 0,785 & 0,7773 & 0,7768 & 0,7471 & 0,74 & - & - & - \\
\hline \multirow{2}{*}{$\begin{array}{c}10^{t h} \text { RUNNING } \\
\text { PARETO FRONT }\end{array}$} & $P_{T O T A L}(\mathrm{~kW})$ & 5826,4 & 5833,9 & 5852,1 & 5922,2 & 5955,3 & 6412,6 & 6632,1 & - & - \\
\hline & $V U F_{M A X}(\%)$ & 0,8818 & 0,785 & 0,7773 & 0,7768 & 0,7471 & 0,6776 & 0,6584 & - & - \\
\hline
\end{tabular}

Fig. 25 shows all Pareto fronts for 200 generations, each color of Fig. 25a represents a different front. The 10 darker results of Fig. 25b represent the best solutions of the fronts. 


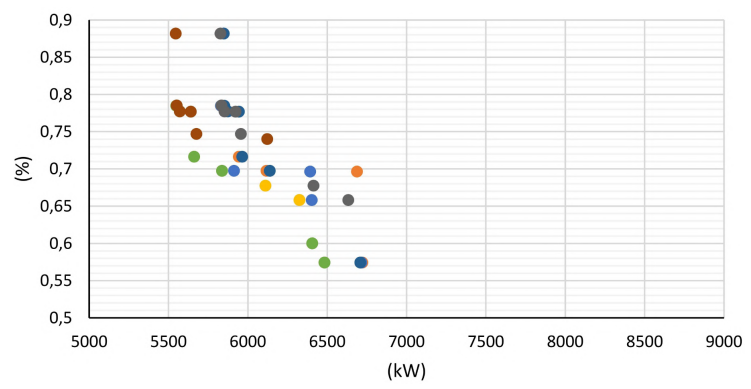

(a) 10 fronts achieved.

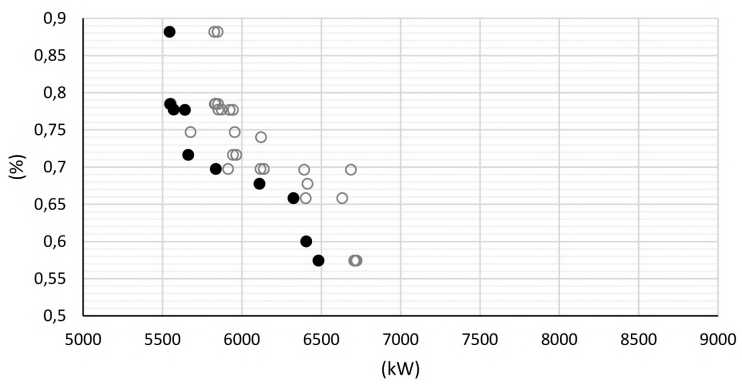

(b) Best solutions identified.

Figure 25: Superimposed results of NSGA-II (for 200 generations).

\subsubsection{Comparison of algorithms}

In order to observe the performance of each proposed algorithm, either for 100 or 200 generations, the best results of the 10 Pareto fronts of GAWS and NSGA-II are compared. Table 11 shows the best solutions found throughout the 10 fronts of each case.

Table 11: Best solutions' magnitudes out of the 10 fronts.

\begin{tabular}{|c|c|c|c|c|c|c|c|c|c|c|c|c|}
\hline \multirow{2}{*}{$\begin{array}{c}\text { GAWS } \\
100 \text { generations }\end{array}$} & $P_{T O T A L}(\mathrm{~kW})$ & 5712,2 & 5719,6 & 5793,2 & 5934 & 6125,4 & 6279,6 & 6328,4 & 6468,4 & 6476,6 & 6642,5 & 6766,9 \\
\hline & $V U F_{M A X}(\%)$ & 0,785 & 0,7848 & 0,7783 & 0,7471 & 0,746 & 0,7386 & 0,7085 & 0,6998 & 0,6584 & 0,6002 & 0,5742 \\
\hline \multirow{2}{*}{$\begin{array}{c}\text { NSGA-II } \\
100 \text { generations }\end{array}$} & $\mathrm{kW})$ & 5687,1 & 5964,3 & 6068,6 & 6543,6 & 6554,4 & - & - & - & - & - & \\
\hline & $V U F_{M A X}(\%)$ & 0,7471 & 0,7164 & 0,6975 & 0,6056 & 0,5742 & - & - & - & - & - & \\
\hline \multirow{2}{*}{$\begin{array}{c}\text { GAWS } \\
200 \text { generations }\end{array}$} & $(\mathrm{kW})$ & 5580,9 & 5603,9 & 5697 & 5899,9 & 5969 & 6209 & 6422,5 & 6538,1 & 6675,1 & - & - \\
\hline & $V U F_{M A X}(\%)$ & 0,785 & 0,7773 & 0,7471 & 0,7366 & 0,7164 & 0,6975 & 0,6801 & 0,5946 & 0,5742 & - & - \\
\hline \multirow{2}{*}{$\begin{array}{c}\text { NSGA-II } \\
200 \text { generations }\end{array}$} & $H_{L}(\mathrm{~kW})$ & 5544,7 & 5548,1 & 5570,5 & 5640,6 & 5661,7 & 5836,1 & 6110 & 6324,8 & 6404,9 & 6481,9 & - \\
\hline & VUF $M A X(\%)$ & 0,8818 & 0,7848 & 0,7773 & 0,7768 & 0,7164 & 0,6975 & 0,6776 & 0,6584 & 0,6002 & 0,5742 & - \\
\hline
\end{tabular}

Fig. 26 depicts the comparison between GAWS and NSGA-II for 100 generations. Fig. 26a compares the average running time of each method. Each algorithm execution of NSGA-II took approximately 452 seconds, and achieving the 10 optimized fronts required 10 algorithm executions in approximately 4520 seconds (1h 15min 20s). On the other hand, one single run of the GAWS took nearly 257 seconds, finding the 10 optimized fronts required 110 algorithm executions in approximately 28270 seconds $(7 \mathrm{~h} 51 \mathrm{~min} 10 \mathrm{~s})$. There is a huge difference in the overall running time between the methods; the difference is nearly 23750 seconds (6h 35min 50s) in favor of NSGA-II.

Fig. $26 \mathrm{~b}$ shows the best solutions of each method found throughout the 10 fronts. Five solutions form the NSGA-II front while GAWS has a larger front with 11 solutions. Despite GAWS was able to find more results, the NSGA-II solutions dominate most of the GAWS results, except the marked solution, emphasizing the advantage of using NSGA-II over GAWS.

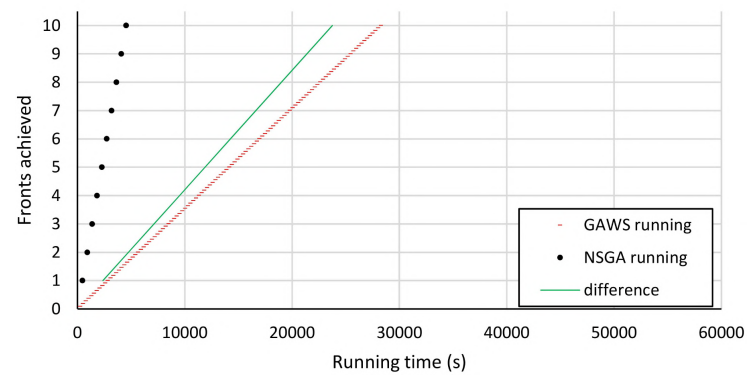

(a) Average execution time.

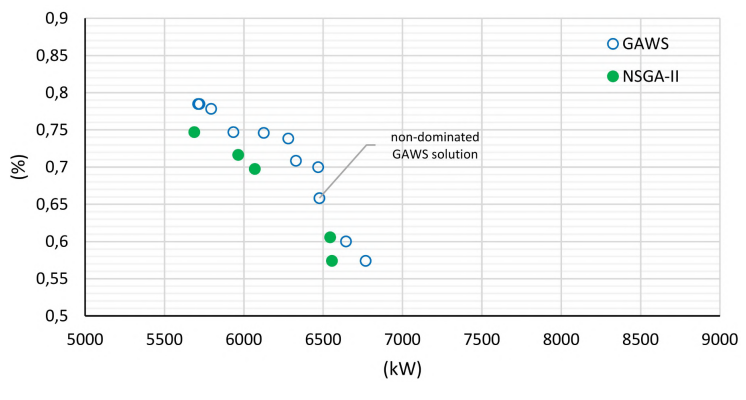

(b) Best solutions identified.

Figure 26: Comparison results between GAWS and NSGA-II (for 100 generations).

In Fig. 27, the comparison between GAWS and NSGA-II for 200 generations is made. The average running time of each method is shown in Fig. 27a. Each execution of NSGA-II took approximately 948 seconds, and achieving the 10 optimized fronts required 10 algorithm executions in approximately 9480 seconds ( $2 \mathrm{~h} 38 \mathrm{~min})$. On the other hand, one single run of the GAWS took nearly 545 seconds, finding the 10 optimized fronts required 110 algorithm executions in approximately 59950 seconds (16h 39min 10s). Again, 
there is a huge difference in the overall running time between the methods; the difference is nearly 50470 seconds (14h 01min 10s).

The best solutions of each method found throughout the 10 fronts are depicted in Fig. 27b. In the 200 generations case, the NSGA-II algorithm found more solutions than the GAWS solutions, 10 against 9 solutions. In addition, the NSGA-II solutions dominate all GAWS solutions, experimentally proving the advantage of using NSGA-II.

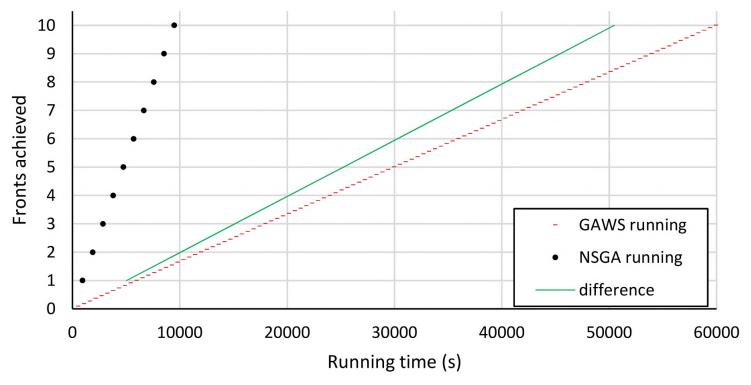

(a) Average execution time.

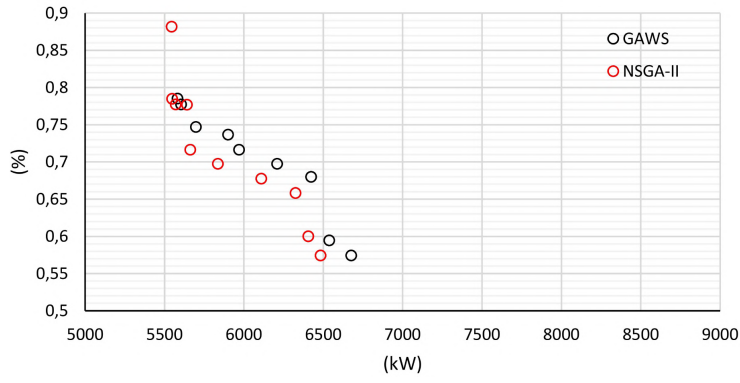

(b) Best solutions identified.

Figure 27: Comparison results between GAWS and NSGA-II (for 200 generations).

Fig. 28 depicts the best configurations found throughout the 10 fronts of each case. Comparing all fronts, it is clearly noted that the Red front (NSGA-II for 200 generations) dominates all other results.

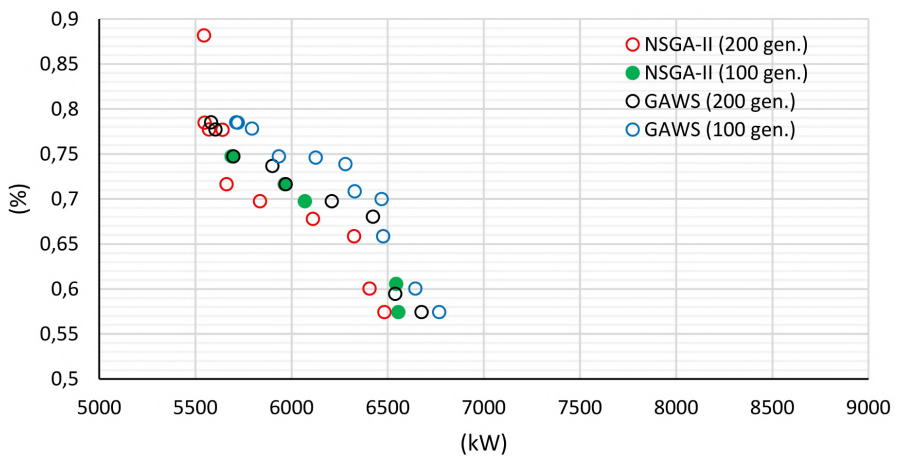

Figure 28: Best configurations found by each method.

Given that the Power Losses values are considerable larger than the Unbalanced Voltage measures, we decided to normalize both objective functions before calculating the corresponding Hypervolume Indicator. Therefore, both objective functions are divided by the largest value of all fronts, i.e. Power Losses values are divided by $6766.9 \mathrm{~kW}$ while VUF is divided by 0.8818 . Fig. 29 displays the normalized results and the reference point $(\mathrm{P})$ set on coordinates $(1.1,1.1)$.

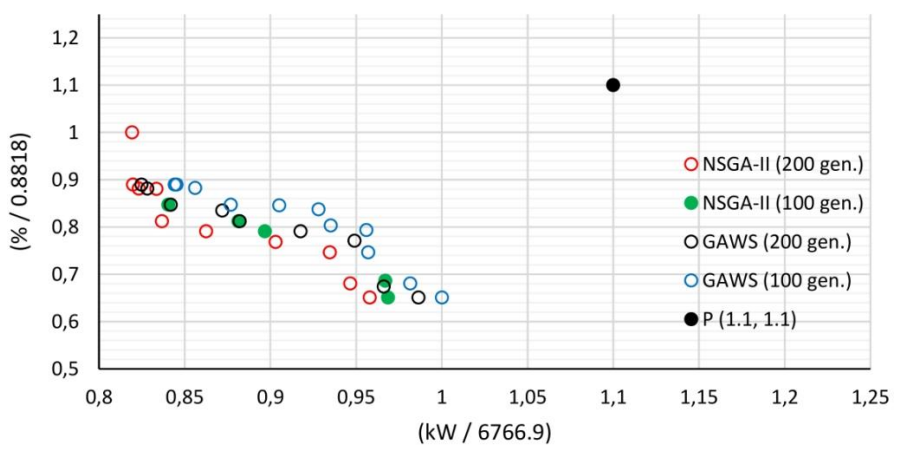

Figure 29: Best configurations normalized and reference point $(\mathrm{P})$.

Now, the equation (11) is applied to determine each HV. The results achieved are as follows.

$$
H V_{G A W S-100}=0,0896
$$




$$
\begin{gathered}
H V_{N S G A I I-100}=0,0961 \\
H V_{G A W S-200}=0,0992 \\
H V_{N S G A I I-200}=0,1069
\end{gathered}
$$

where $V_{G A W S-100}<H V_{N S G A I I-100}<H V_{G A W S-200}<H V_{N S G A I I-200}$.

The performance of the four Pareto Fronts are evaluated comparing their HV, and again, it is verified that NSGA-II has a better performance than GAWS.

\section{Conclusion and Future Work}

For the first time in the literature, this paper presents a comparative study of two approaches in a multiobjective context to optimize an unbalanced three-phase distribution reconfiguration system. The proposed models have different perspectives to find the Pareto-optimal solutions. On one hand, GAWS adapts the multi-objective problem into a single objective GA and the algorithm is running several times to find different solutions. On the other hand, NSGA-II algorithm is able to find multiple Pareto-optimal solutions in one single run.

Besides GAWS and NSGA-II, other algorithms were combined to achieve the optimization model, such as the three-phase power flow algorithm, as well as Prim and Kruskal algorithms. The bibliographic information used shows that Forward and Backward Sweep is one of the most effective three-phase power flow algorithms for distribution systems, so this algorithm was applied to evaluate all individuals during the reconfiguration process. In addition, the Prim and Kruskal algorithms were compared, and it was found that in the classical approaches, the Prim's algorithm is faster on dense graphs; while Kruskal's is faster on sparse graphs, but Prim's algorithm can be improved using pairing heaps, which makes Prim's implementation the fastest practical choice for both sparse and dense graphs. Thus, the improved version of Prim algorithm was implemented to fix infeasible configurations generated by genetic operators.

Experimental results show that despite a single run of GAWS is faster than the NSGA-II algorithm, finding most solutions of the Pareto set takes longer. In the first study, a small distribution system was used, which gave the chance of exploring a large part of the search space, and it was demonstrated that sometimes the GAWS might be unable to find all Pareto-front solutions. The second study case tested the algorithms in a complex system, with a larger search space; in this study, results show that the NSGA-II normally leads to better results in optimizing unbalanced three-phase distribution systems through reconfiguration.

In conclusion, from the presented experimental results we can recommend the use of NSGA-II to solve the reconfiguration problem when a set of configurations is needed, because a single run can reach most solutions giving a variety of good configurations to the decision maker.

Future works should consider that distribution systems are subject to suddenly suffer power outages, which result in tremendous economic losses. In these cases, there is no much time to take decisions and having a quick response is necessary; therefore, other reconfiguration algorithms should be tested under emergency situations. Furthermore, more constraints may be added to the reconfiguration problem, such as time of power restoration, number of switch operations, availability of remote operation equipment and power crews, among other alternatives.

\section{References}

[1] H. Schmidt, N. Ida, N. Kagan, and J. Guaraldo, "Fast reconfiguration of distribution systems considering loss minimization," IEEE Transactions on Power Systems, vol. 20, no. 3, pp. 1311-1319, Aug 2005. [Online]. Available: http://ieeexplore.ieee.org/document/1490582/

[2] A. Merlin and H. Back, "Search for a Minimal-Loss Operating Spanning Tree Configuration in an Urban Power Distribution System," Power System Computation Conference (PSCC), no. 5, Sept. 1975.

[3] D. Shirmohammadi and H. Hong, "Reconfiguration of electric distribution networks for resistive line losses reduction," IEEE Transactions on Power Delivery, vol. 4, no. 2, pp. 1492-1498, Apr. 1989. [Online]. Available: http://ieeexplore.ieee.org/document/25637/

[4] S. Civanlar, J. Grainger, H. Yin, and S. Lee, "Distribution Feeder Reconfiguration for Loss Reduction," IEEE Transactions on Power Delivery, vol. 3, no. 3, pp. 1217-1223, July 1988. [Online]. Available: http://ieeexplore.ieee.org/document/193906/ 
[5] K. Nara, A. Shiose, M. Kitagawa, and T. Ishihara, "Implementation of genetic algorithm for distribution systems loss minimum re-configuration," IEEE Transactions on Power Systems, vol. 7, no. 3, pp. 1044-1051, Aug. 1992. [Online]. Available: http://ieeexplore.ieee.org/document/207317/]

[6] H. Kim, Y. Ko, and K.-H. Jung, "Artificial neural-network based feeder reconfiguration for loss reduction in distribution systems," IEEE Transactions on Power Delivery, vol. 8, no. 3, pp. 1356-1366, July 1993. [Online]. Available: http://ieeexplore.ieee.org/document/252662/

[7] H.-C. Chang and C.-C. Kuo, "Network reconfiguration in distribution systems using simulated annealing," vol. 29, pp. 227-238, 5 1994. [Online]. Available: https://www.sciencedirect.com/science/ article/pii/0378779694900183

[8] C.-T. Su, C.-F. Chang, and J.-P. Chiou, "Distribution network reconfiguration for loss reduction by ant colony search algorithm," Electric Power Systems Research, vol. 75, no. 2-3, pp. 190-199, Aug. 2005. [Online]. Available: https://www.sciencedirect.com/science/article/pii/S0378779605001021

[9] C. A. Coello, G. B. Lamont, and D. A. V. Veldhuizen, Evolutionary Algorithms for Solving Multi-Objective Problem, 2nd ed. New York: Springer, 2007. [Online]. Available: https://www.springer.com/gp/book/9780387332543

[10] R. Vitorino, H. Jorge, and L. Neves, "Loss and reliability optimization for power distribution system operation," Electric Power Systems Research, vol. 96, no. Supplement C, pp. 177 - 184, 2013. [Online]. Available: https://www.sciencedirect.com/science/article/pii/S0378779612003203

[11] B. Amanulla, S. Chakrabarti, and S. Singh, "Reconfiguration of power distribution systems considering reliability and power loss," IEEE Transactions on Power Delivery, vol. 27, no. 2, pp. 918-926, April 2012. [Online]. Available: http://ieeexplore.ieee.org/document/6138890/

[12] R. Marler and J. Arora, "The weighted sum method for multi-objective optimization: New insights," vol. 41, pp. 853-862, 06 2010. [Online]. Available: https://link.springer.com/article/10.1007/ s00158-009-0460-7

[13] B. Tomoiagă and D. Micu, "A comparative study of pareto optimal approaches for distribution system reconfiguration," in 2014 49th International Universities Power Engineering Conference (UPEC), Sept 2014, pp. 1-6. [Online]. Available: http://ieeexplore.ieee.org/document/6934784/

[14] A. Mazza, G. Chicco, and A. Russo, "Comparison of multi-objective optimization approaches for distribution system reconfiguration," in 2013 IEEE Grenoble Conference, June 2013, pp. 1-6. [Online]. Available: http://ieeexplore.ieee.org/document/6652482/

[15] J. Horn, N. Nafpliotis, and D. Goldberg, "A Niched Pareto Genetic Algorithm for Multiobjective Optimization," In Proceedings of the 1st IEEE Conference on Evolutionary Computation, IEEE World Congress on Computational Intelligence, vol. 1, pp. 82-87, 1994. [Online]. Available: http://ieeexplore.ieee.org/document/350037/

[16] E. Zitzler and L. Thiele, "Multiobjective evolutionary algorithms: a comparative case study and the strength pareto approach," IEEE Transactions on Evolutionary Computation, vol. 3, no. 4, pp. 257-271, Nov 1999. [Online]. Available: http://ieeexplore.ieee.org/document/797969/

[17] E. Zitzler, M. Laumanns, and L. Thiele, "SPEA2: Improving the Strength Pareto Evolutionary Algorithm," Computer Engineering and Networks Laboratory (TIK) Department of Electrical Engineering Swiss Federal Institute of Technology (ETH) Zurich ETH Zentrum, no. 103, May 2001. [Online]. Available: https://pdfs.semanticscholar.org/6672/8d01f9ebd0446ab346a855a44d2b138fd82d. pdf

[18] C. Fonseca and P. Fleming, "Genetic Algorithms for Multiobjective Optimization: Formulation, Discussion, Generalization," In Genetic Algorithms: Proceedings of the Fifth International Conference, July 1993. [Online]. Available: https://www.researchgate.net/publication/2246029_ Genetic_Algorithms_for_Multiobjective_Optimization_Formulation_Discussion_and_Generalization

[19] N. Srivinas and K. Deb, "Multi objective Optimization Using Non Sorting in Genetic A1gorithms," Journal of Evolutionary Computation, vol. 2, no. 3, pp. 221-248. [Online]. Available: http://ieeexplore.ieee.org/document/6791727/ 
[20] K. Deb, A. Pratap, S. Agarwal, and T. Meyarivan, "A Fast and Elitist Multiobjective Genetic Algorithm: NSGA-II," IEEE Transactions on Evolutionary Computation, vol. 6, no. 2, pp. 182-197, April 2002. [Online]. Available: http://ieeexplore.ieee.org/document/996017/

[21] C. von Lücken, B. Barán, and C. Brizuela, "A survey on multi-objective evolutionary algorithms for many-objective problems," Computational Optimization and Applications, vol. 58, no. 3, pp. 707-756, July 2014. [Online]. Available: https://link.springer.com/article/10.1007/s10589-014-9644-1]

[22] A. von Jouanne and B. Banerjee, "Assessment of voltage unbalance," IEEE Transactions on Power Delivery, vol. 16, no. 4, pp. 782-790, Oct 2001. [Online]. Available: http: //ieeexplore.ieee.org/document/956770/

[23] C.-Y. Lee, B.-K. Chen, W.-J. Lee, and Y.-F. Hsu, "Effects of various unbalanced voltages on the operation performance of an induction motor under the same voltage unbalance factor condition," Industrial and Commercial Power Systems Technical Conference, pp. 51-59, 1997. [Online]. Available: http://ieeexplore.ieee.org/document/595989/

[24] R. Jiménez, T. Serebrisky, and J. Mercado, "Sizing Electricity Losses in Transmission and Distribution Systems in Latin America and the Caribbean," Inter-American Development Bank, p. 41, Nov. 2014. [Online]. Available: https://publications.iadb.org/bitstream/handle/11319/6689/ Power-electricity-loss.pdf?sequence $=1$

[25] W. Kersting and D. Mendive, "An application of ladder network theory to the solution of three-phase radial load-flow problems," IEEE Power Eng. Soc. Winter Meeting, vol. PAS-86, Jan. 1976.

[26] R. C. Prim, "Shortest connection networks and some generalizations," Bell System Technical Journal, vol. 36, no. 6, pp. 1389-1401, Nov. 1957. [Online]. Available: http://ieeexplore.ieee.org/document/ $6773228 /$

[27] J. B. Kruskal, "On the shortest spanning subtree of a graph and the traveling salesman problem," Proceedings of the American Mathematical Society, vol. 7, no. 1, pp. 48-50, Feb. 1956. [Online]. Available: https://www.jstor.org/stable/2033241?seq=1\#page_scan_tab_contents

[28] J. Cebrian and N. Kagan, "Evolutionary algorithms for the reconfiguration of radial distribution networks considering long interruption and voltage sag disruption costs," 13th International Conference on Harmonics and Quality of Power, Sept./Oct. 2008. [Online]. Available: http: //ieeexplore.ieee.org/document/4668814/

[29] M. Guimaraes, C. Castro, and R. Romero, "Distribution systems operation optimisation through reconfiguration and capacitor allocation by a dedicated genetic algorithm," IET Generation, Transmission \& Distribution, vol. 4, no. 11, pp. 1213-1222, Nov. 2010. [Online]. Available: http://ieeexplore.ieee.org/document/5593262/

[30] T. Sudhakar and K. Srinivas, "Power system restoration based on Kruskal's algorithm," 1st International Conference on Electrical Energy Systems, pp. 281-287, Jan. 2011. [Online]. Available: http://ieeexplore.ieee.org/document/5725343/

[31] W. H. Kersting, Distribution System Modeling and Analysis, 3rd ed. Boca Raton, London, New York: CRC Pres Taylor \& Francis, 2012.

[32] E. P. Characteristics and E. Compatibility, "Application guide to the European Standard EN 50160 on "voltage characteristics of electricity supplied by public distribution systems", Union of the Electricity Industry," EURELECTRIC, p. 42, July 1995. [Online]. Available: http://www.pasma.com.au/pdf/GuideToEN50160.pdf

[33] A. N. de Energia Elétrica ANEEL, "Procedimentos de Distribuição de Energia Elétrica no Sistema Elétrico Nacional - PRODIST," Módulo 8 - Qualidade da Energia Elétrica, p. 62. [Online]. Available: http://www2.aneel.gov.br/arquivos/pdf/modulo8_revisao_1_retificacao_1.pdf

[34] M. H. J. Bollen, "Definitions of voltage unbalance," IEEE Power Engineering Review, vol. 22, no. 11, pp. 49-50, Nov 2002. [Online]. Available: http://ieeexplore.ieee.org/stamp/stamp.jsp?tp= \&arnumber $=4311797$

[35] D. E. Goldberg, Genetic Algorithms in Search, Optimization, and Machine Learning, 1st ed. Boston: Addison-Wesley, 1989. 
[36] B. Tomoiaga and M. Chindris, "Reconfiguration of distribution networks with dispersed generation by pareto optimality and evolution strategies," 7th Balkan Power Conference, pp. 1-6, Sept. 2008. [Online]. Available: https://www.researchgate.net/publication/268813475_Reconfiguration_of_ Distribution_Networks_with_Dispersed_Generation_by_Pareto_Optimality_and_Evolution_Strategies

[37] O. Grodzevich and O. Romanko, "Normalization and Other Topics in Multi-Objective Optimization," Proceedings of the Fields-MITACS Industrial Problems Workshop, pp. 89-101, 2006. [Online]. Available: http://www.maths-in-industry.org/miis/233/

[38] N. Razali and J. Geraghty, "Genetic Algorithm Performance with Different Selection Strategies in Solving TSP," World Congress on Engineering, vol. II, July 2011. [Online]. Available: https://pdfs.semanticscholar.org/010b/545848cfd29fe6e83987d494fdd00b486229.pdf

[39] N. Riquelme, C. Von Lücken, and B. Barán, "Performance metrics in multi-objective optimization," in 2015 Latin American Computing Conference (CLEI), Oct 2015, pp. 1-11. [Online]. Available: https://ieeexplore.ieee.org/document/7360024

[40] E. Zitzler and L. Thiele, "Multiobjective optimization using evolutionary algorithms - a comparative case study," in Parallel Problem Solving from Nature - PPSN V, A. E. Eiben, T. Bäck, M. Schoenauer, and H.-P. Schwefel, Eds. Berlin, Heidelberg: Springer Berlin Heidelberg, 1998, pp. 292-301. [Online]. Available: https://link.springer.com/chapter/10.1007/BFb0056872

[41] S. S. Skiena, The Algorithm Design Manual, 2nd ed. Springer-Verlag London, 2008. [Online]. Available: https://www.springer.com/gp/book/9781848000698\#aboutBook

[42] T. H. Cormen, C. E. Leiserson, R. L. Rivest, and C. Stein, Introduction to Algorithms, 3rd ed. Cambridge (Massachusetts), London (England): The MIT Press, 2009.

[43] G. Soothill, The Euclidean Steiner Problem. Department of Mathematical Science, Durham University, England, 2010. [Online]. Available: http://fourier.dur.ac.uk/Ug/projects/highlights/CM3/ Soothill_Steiner_report.pdf

[44] Ching-Tzong Su and Chu-Sheng Lee, "Network reconfiguration of distribution systems using improved mixed-integer hybrid differential evolution," IEEE Transactions on Power Delivery, vol. 18, no. 3, pp. 1022-1027, July 2003. [Online]. Available: https://ieeexplore.ieee.org/document/1208393 